\title{
STADT-RAUM UND SOZIALSTRUKTUR
}

\section{ÜBerlegungen Zu Quellen, Methoden und Problemen AN DEN BEISPIELEN GREIFSWALD UND OSNABRÜCK}

\author{
von Karsten Igel
}

\begin{abstract}
Die soziale Struktur und Topographie gehören zu den zentralen Fragen der Stadtgeschichtsforschung. Im Anschluss an die sozialwissenschaftliche Wende in der Geschichtswissenschaft erfolgte in den 1970er und 80er Jahren eine ausgiebige und weitgehend fruchtbare Diskussion um die zur Erforschung der Sozialstruktur der mittelalterlichen Stadt geeigneten Quellen und Wege.' Ohne hier den ganzen Diskussionsweg noch einmal aufzurollen, sei hier aber doch darauf hingewiesen, dass jede Wende natürlich die Gefahr in sich birgt, anschließend über das eigentliche Ziel hinauszuschießen. Wenn Helge Steenweg in seiner wichtigen Arbeit zu Göttingen um 1400 zusammenfassend feststellt, dass eine vergleichbare
\end{abstract}

\footnotetext{
' Vgl. Wilfried EHBRECHT, Zu Ordnung und Selbstverständnis städtischer Gesellschaft im späten Mittelalter, in: BDLG 110, 1974. S. 83-103; Jürgen El.l.ERMEYER. Sozialgruppen. Selbstverständnis. Vermögen und städtische Verordnungen, in: BDLG 113, 1977, S. 203-275; DERS., „Schichtung“ und „Sozialstruktur“ in spätmittelalterlichen Städten. Zur Verwendbarkeit sozialwissenschaftlicher Kategorien in der historischen Forschung, in: Geschichte und Gesellsehaft 6, 1980, S. 125-149; DERS., Grundeigentum, Arbeits- und Wohnverhältnisse. Bemerkungen zur Sozialgeschichte spätmittelalterlicher Städte, in: Lübecker Schriften zur Archäologie und Kulturgeschichte 4, 1980, S. 71-95; DERS., Vorindustrielle Städte als Forschungsaufgabe, in: Die alte Stadt 7, 1980, S. 276-296; Erich MASCHKE, Die Schichtung der mittelalterlichen Stadtbevölkerung Deutschlands als Problem der Forschung, in: DERS., Städte und Menschen. Beiträge zur Geschichte der Stadt, der Wirtschaft und Gesellschaft 1959-1977 (VSWG Beiheft 68), Wiesbaden 1980, S. 157-169; DERS., Verfassung und soziale Kräfte in der deutschen Stadt des späten Mittelalters, vornehmlich in Oberdeutschland, ebd.. S. 170-274; DERS., Mittelschichten in deutschen Städten des Mittelalters, ebd., S. 275-305; DERS.. Die Unterschichten der mittelalterlichen Städte Deutschlands, ebd., S. 306-379: Ders., Soziale Gruppen in der deutschen Stadt des späten Mittelalters, in: Über Bürger, Stadt und städtische Literatur im Spätmittelalter, hg. von Josef FLECKENSTEIN und K. STACKMANN. Göttingen 1980. S. 127-145; Erdmann WEYRAUCH. Über soziale Schichtung, in: Städtische Gesellschaft und Reformation, hg. von Ingrid BÁTORI (Spätmittelalter und Frühe Neuzeit. Tübinger Beiträge zur Geschichtsforschung Bd. 12), Stuttgart 1980, S. 5-57; Rolf HAMMEL, Hauseigentum im spätmittelalterlichen Lübeck. Methoden zur sozial- und wirtschaftsgeschichtlichen Auswertung der Lübecker Oberstadtbuchregesten, in: Lübecker Schriften zur Archäologie und Kulturgeschichte 10, 1987, S. 85-300.
} 
Untersuchung nur noch zu Köln und Lübeck möglich scheint, ${ }^{2}$ ist dies nicht nur falsch, da die Quellenlage zu diesem Zweck beispielsweise in Rostock erheblich besser als in Göttingen und Lübeck ist ${ }^{3}-$ zu Höxter bereits eine beispielhafte Arbeit vorlag und auch eine ganze Zahl anderer Städte sich durchaus sehen lassen kann, wie das Beispiel Greifswald zeigt, ${ }^{4}$ er wirft damit auch - ohne es zu bemerken - die Frage nach Sinn und Unsinn einer solchen Untersuchung auf. Denn wenn eine gewünschte Detailtiefe nur für einige wenige Städte erreichbar ist (für Göttingen dabei auch nur in schmalen Zeitschnitten durchgeführt wurde), geht eine wesentliche Forderung an die wissenschaftliche Forschung verloren: die notwendige Vergleichbarkeit der Befunde mit möglichst vielen anderen Beispielen. Wie sonst ist es möglich festzustellen, ob die gewonnenen Ergebnisse allgemeintypisch für die mittelalterliche Stadt bzw. einen Stadttyp sind oder eine Besonderheit der jeweiligen Stadt darstellen? Da bislang nur wenige Arbeiten vorliegen, ${ }^{5}$ die eine ganze Stadt und nicht nur einzelne Viertel odrar Dtraßenzuige unter den Aspekten Sozialstruktur und Sozialtopographie in den Blick nehmen, ${ }^{6}$ besteht somit leicht die Gefahr, dass auf der Basis weniger oder besser einzelner Beispiele ein Bild der mittel-

${ }^{2}$ Helge STEENwEG, Göttingen um 1400. Sozialstruktur und Sozialtopographie einer mittelalterlichen Stadt, Göttingen 1994, hier S. 305.

${ }^{3}$ Zur Rostocker Quellenlage vgl. Wilhelm EBEL, Lübisches Recht, Lübeck 1971, S. $421 \mathrm{f}$ - - Die SchoBregister und das Häuserbuch der Rostocker Altstadt werden neuerdings von Frau Julia Hamelmann (Münster) im Rahmen ihrer Dissertation bearbeitet.

${ }^{+}$Vgl. Karsten IGEL, Greifswalder und Greifswald um 1400. Stadt-Raum im Spiegel des Greifswalder liber hereditatum (1351-1452), Diss. phil. Münster 2002 (Druck in der Reihe ".Städteforschung" voraussichtlich 2005); DERS., Greifswald um 1400). Zur Stadtgestalt und Sozialtopographie Greifswalds im Spätmittelalter, in: BaltStud. 88, 2002, S. 20-42; DERS., Zur Topographie und Sozialstruktur Greifswalds um 1400. Der Greifswalder liber hereditatum (1351-1452), in: Die Sozialstruktur und Sozialtopographie der vorindustriellen Stadt, hg. von Andreas RANFT und Mathias MEINHARDT, Berlin 2004. S. 233-252.

${ }^{5}$ Als Beispiele: Heinrich Rüthing. Höxter um 1500. Analyse einer Stadtgesellschaft (Studien und Quellen zur westfälischen Geschichte 22), Paderborn 1986; STEENWEG, Göttingen um 1400 (wie Anm. 2); Ernst PIPER, Der Stadtplan als Grundriß der Gesellschaft. Topographie und Sozialstruktur in Augsburg und Florenz um 1500. Frankfurt (Main)/New York 1982; Willi SCHOCH, Die Bevölkerung der Stadt St. Gallen im Jahre 1411. Eine sozialgeschichtliche und sozialtopographische Untersuchung (St. Galler Kultur und Geschichte 28), St. Gallen 1997; Rolf Hammel-Kiesow. Die Entstehung des sozialräumlichen Gefüges der mittelalterlichen Großstadt Lübeck. Grund und Boden. Baubestand und gesellschaftliche Struktur, in: Sozialstruktur und Sozialtopographie, hg. von RANFT/MEINHARDT (wie Anm. 4); als neueren Überblick demnächst: Sozialstruktur und Sozialtopographie, hg. RANFT/ MEINHARDT (wie Anm. 4); zur neueren polnischen Forschung: Roman CZAJA, Neue Erkenntnisse zur Sozialtopographie der spätmittelalterlichen Hansestädte im Ostseeraum, in: Vergleichende Ansätze in der hansischen Geschichtsforschung, hg. von Rolf HAMMEL-KIESow (Hansische Studien 13), Trier 2002, S. 273-284.

${ }^{6}$ Im Blick auf die Forschungslage ergibt sich leicht der Eindruck, es gebe mehr Beiträge zur Methode als eigentliche Untersuchungen zu einzelnen Städten. 
alterlichen Stadt konstruiert wird, das nicht unbedingt repräsentativ ist. Dies gilt natürlich nicht nur für den sozialgeschichtlichen Aspekt, sondern allgemein für die Entwicklung der Städte. So wurde Lübeck allzu leicht zum Vorbild für die Städtegründungen im Ostseeraum gemacht und so auch zum Maßstab für die soziale Strukturierung des städtischen Raumes, ${ }^{7}$ eine These, der von Rolf Hammel-Kiesow überzeugend widersprochen wurde $^{8}$

Das Problem liegt weniger an einem Mangel geeigneter Quellen zur spätmittelalterlichen Stadtgesellschaft, als in einèr zu geringen Berücksichtigung des vorhandenen Quellenmaterials, das in vielen Städten noch kaum eingehender betrachtet in den Archiverr liegt, in der methodischen Diskussion. Diese muss wohl zuerst einmal zurück auf die Füße, sprich die Quellengrundlage gestellt werden. Wichtigstes Kriterium dafür ist, dass eine Vergleichbarkeit für eine große Zahl von Städten gegeben sein muss und zudem der Arbeitsaufwand für eine einzelne Stadt vertretbar und die Arbeit innerhalb eines überschaubaren Zeitraumes abschließbar sein sollte. Was freilich noch lange keine „Stadtgeschichtsforschung light“ bedeuten muss und darf. Um die stark differierende Quellenlage zu berücksichtigen, wäre es ratsam, für die Untersuchung eine Struktur unterschiedlich tief detaillierter Betrachtungsebenen zu wählen, so dass sich für den Quervergleich zwischen Städten zumindest jeweils eine geeignete Vergleichsebene finden ließe.

Im folgenden soll hier weniger eine neue einheitliche Methode diskur tiert, als vielmehr der Blick auf die verfügbaren historischen, archäologischen und bauhistorischen Quellen und die Möglichkeiten ihrer Verknüpfung gerichtet werden, die sich für eine sozialgeschichtliche Auswertung unter dem Aspekt des städtischen Raumes eignen. Als illustrierende Beispiele werden zwei gegensätzliche Städte vorgestellt: die mittelgroße Seestadt Greifswald und mit der Bischofsstadt Osnabrück eine der vier großen

\footnotetext{
${ }^{7}$ Vgl. Fritz RÖRIG, Die Stadt in der deutschen Geschichte, in: ZVLGA 33, 1952, S. 658-680, hier S. 665: Wolfgang BRAunfELS, Die Kunst im Heiligen Römischen Reich, Bd. III: Reichsstädte. Grafschaften, Reichsklöster, München 1981, S. 265; Heinz SToob, Über Wachstumsvorgänge-und' Hafenausbau bei hansischen See- und Flußhäfen im Mittelalter, in: See- und Flußhäfen vom Hochmittelalter bis zur Industrialisierung, hg. von Heinz Sтоов (Städteforschung A/24), Köln/Wien 1986, S. 1-65, hier S. 46; Roman CZAJA, Elbing, in: Die Hanse. Lebenswirklichkeit und_Mythos. Bd, 1, hg. yon Jörgen BRACKER. Hamburg. 1989, S. 280-284, hier S. 280.

${ }^{8}$ Rolf HAMMEL-KIESOW, Lübeck als Vorbild zahlreicher Städtegründungen im Ostseeraum? Überlegungen zum Verhältnis zwischen geschichtlichen Vorgängen und historiographischer Erklärung, in: Die Stadt im westlichen Ostseeraum. Vorträge zur Stadtgründung und Stadterweiterung im Hohen Mittelalter, hg. von Erich HoFMANN und Frank LubOwITZ (Kieler Werkstücke A/14), Frankfurt (Main) 1995, S. 263-305.
} 


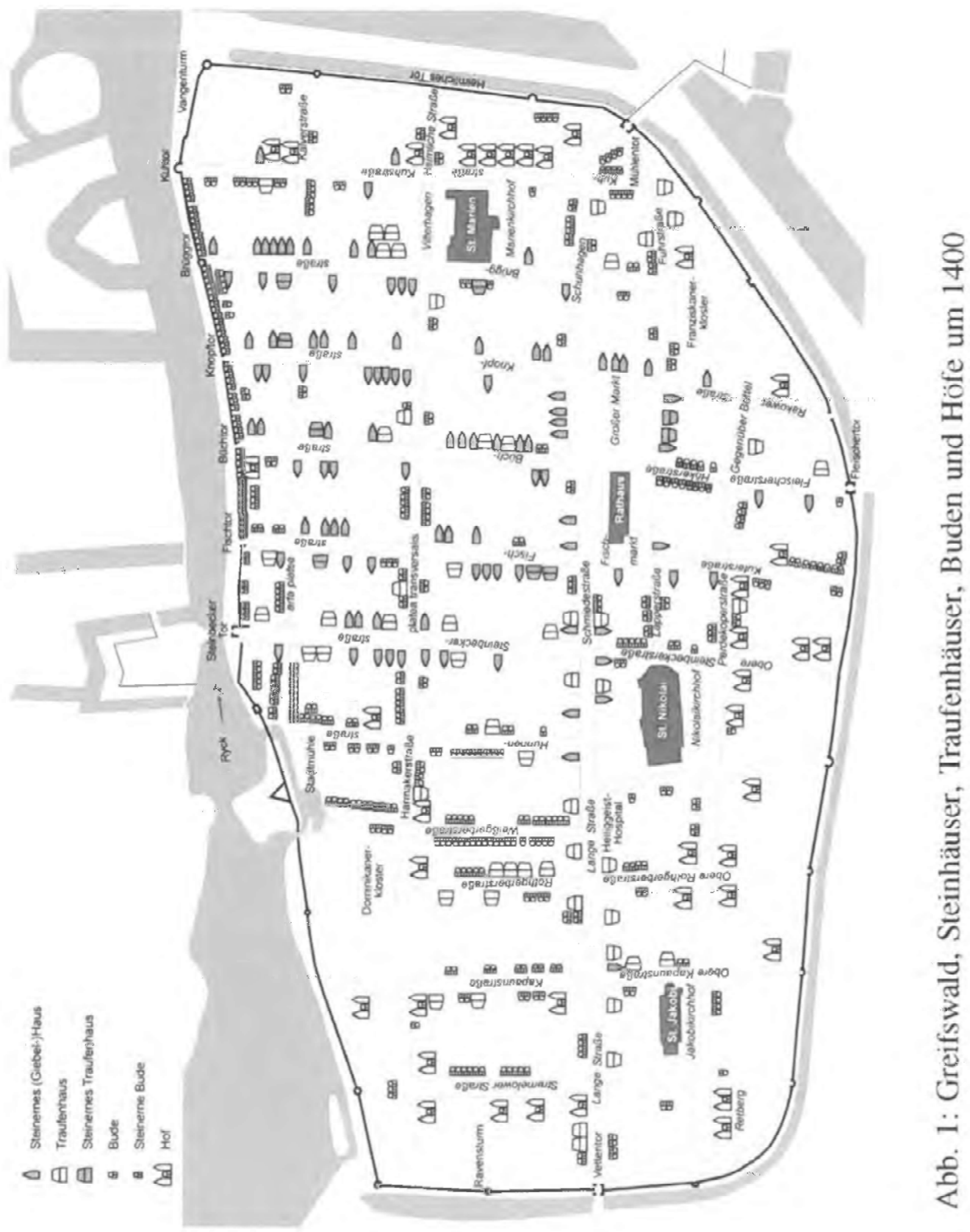

westfälischen Städte. Die Auswahl ergibt sich nicht nur aus den Forschungsschwerpunkten des Verfassers, sondern wird auch durch die jeweilige interessante örtliche Quellenlage, die unterschiedliche Stadtgenese sowie die sich stark unterscheidenden räumlichen und sozialen Strukturen nahe gelegt. Um dies zu veranschaulichen seien beide Städte vorweg kurz in ihrem Gefüge und ihrer Quellenüberlieferung vorgestellt. 


\section{Greifswald}

Das 1250 privilegierte und auf eine nur wenig ältere Siedlung fußende Greifswald sticht schon durch das sehr gleichmäßige schachbrettartige Straßenraster ins Auge (Abb. 1). Bereits 1264 wurde dic westlich der Weißgerberstraße beginnende Neustadt mit der Altstadt vereinigt und zugleich verfügt, dass die Stadt künftig nur einen Markt haben sollte." Auch in der städtischen Verfassung spielte die Unterscheidung-in Alt- und $\mathbb{N}^{N}$ ustadt keinerlei Rolle. Neben den drei Pfarrkirchen bestanden ein Dominikaner- und ein Franziskanerkloster sowie ein Heiliggeist-Hospital in der Stadt, drei weitere Hospitäler vor den Stadttoren. Das Rathaus entstand in den 1340er Jahren auf einem großen rechteckigen Platz, der zwei Baublöcken innerhalb des Greifswalder Straßenrasters entspricht - ein Vorgängerbau ist aus Quellenbelegen zu vermuten, konnte aber noch nicht lokalisiert werden. Weitere Markt- und öffentliche Einrichtungen befanden sich in den Straßen südlich des Marktplatzes. ${ }^{10}$

Den Kern der Überlieferung bilden die gemäß des lübischen Rechtes. geführten Stadtbücher: Das älteste erhaltene reicht von 1291 bis 1332 und enthält überwiegend Rentenverschreibungen." 1349 setzt ein reines Rentenbuch ein (bis 1442), ${ }^{12}$ folgende Bände fehlen allerdings, und mit dem Jahr 1352 beginnt eine Reihe von drei Erbebüchern, die mit nur kurzen Lücken (1452-1460 und 1676-1683) die Auflassungen von Grundstücken bis zum Ende des 18. Jahrhunderts enthalten. ${ }^{13}$ Daneben liegen ein Kämmereibuch für die Jahre 1360 bis $1411,{ }^{14}$ ein Verzeichnis der Ratsmitglie-

\footnotetext{
${ }^{9}$ Pommersches Urkundenbuch Nr. 514 - 1250 Mai 14: Nr. 757 - 1264 Juni 26; vgl. Joachim WÄCHTER, Die Anfänge Greifswalds im Rahmen der Siedlungsgeschichte, in: Land am Meer. Pommern im Spiegel seiner Geschichte. Roderich Schmidt zum 70. Geburtstag, hg. von Werner BUCHHOLZ und Günther MANGELSDORF, Köln/Weimar/Wien 1995, S. 133-144; Detlef KatTinger, Die Stadtentwicklung vom Ende des 13. Jahrhunderts bis 1500, in: Greifswald. Geschichte der Stadt, hg. von Horst WERNICKE, Schwerin 2000, S. 33-59: Heiko SCHÄFER, Ergebnisse der Stadtkernarchäologie in Greifswald. in: ebd., S. 443-450; Karsten IGEL, Geplant oder gewachsen - ein scheinbarer Widerspruch. Mittelalterliche Stadtentwicklung an den Beispielen Greifswald und Osnabrück, in: Mitteilungen der Deutschen Gesellschaft für Archäologie des Mittelalters und der Neuzeit 15, 2004, S. 17-23.

${ }^{10} \mathrm{Vgl}$. IGEL, Greifswald um 1400 (wie Anm. 4), S. 26-31.

"Das älteste Greifswalder Stadtbuch (1291-1332), bearbeitet von Dietrich W. PoECK (Veröffentlichungen der historischen Kommission für Pommern [V/14), Köln/Weimar/Wien 2000 ,

${ }^{12}$ Stadtarchiv Greifswald (StAG) Rep. 3 Nr. 15.

${ }^{13}$ StAG Rep. 3 Nr. 16, Nr. 17 und Nr. 18; die Regesten der Grundstücksgeschäfte aus dem ersten Stadterbebuch (1351-1452) erscheinen auf einer beigefügten CD-ROM in: IGEL, Greifswalder und Greifswald um 1400 (wie Anm. 4).

${ }^{14}$ StAG Rep. 3 Nr. 33.
} 
der ab 1382, ${ }^{15}$ mehrere Kopiare mit städtischen Privilegien und Urkunden, ${ }^{16}$ Ratswillküren, ${ }^{17}$ Statuten der Handwerksämter ${ }^{18}$ und weitere Bücher mit vermischtem Inhalt vor. ${ }^{19}$ Dagegen fehlen Steuerverzeichnisse nahezu vollständig. In einem einselnen von 1327 wurden die Zahlungen der Handwerksämter nur jeweils in einer Gesamtsumme erfasst, so dass eiry wesentlicher Teil der Stadtbevölkerung anonym bleibt. ${ }^{20}$ Erst ab 1499 setzt eine weitgehend durchgängige Reihe von Grundsteuerlisten ein. ${ }^{21}$ Archäologisch gehört Greifswald inzwischen zu den am besten untersuchten Städten des Ostseeraumes, wobei die wichtigen Grabungen zumindest in Form von Vorberichten publiziert sind. ${ }^{22}$ Ein ähnlich guter Untersuchungsstand besteht von der bauhistorischen Seite, allerdings steht hier mangels finanzieller Mittel die Aufarbeitung leider zurück. ${ }^{23}$ Ergänzt werden diese Befunde durch die Auswertung der Greifswalder Stadtbücher, insbesondere des Stadterbebuches von 1351-1452, die neben den Eigentumsgeschichten zu einzelnen Grundstücken auch Hinweise auf die Entwicklung und Verteilung von Baustrukturen für den Untersuchungszeitraum erbrachte. $^{24}$ Die hier inzwischen gute Forschungslage erlaubt fächerintegrative Untersuchungen auch zu einzelnen Grundstücken und Bau-

${ }^{15}$ StAG Rep. 3 Nr. 21; vgl. Theodor PYL, Genealogien der Greifswalder Ratsmitglieder 1382-1647 (Pommersche Genealogien 5), Greifswald 1896; zu den Ratsmitgliedern bis 1382: Ders., Genealogien der Greifswalder Ratsmitglieder 1250-1382 (Pommersche Genealogien 4), Greifswald 1895.

${ }^{16}$ StAG Rep. 3 Nr. 1, Nr. 2.

${ }^{17}$ StAG Rep. 3 Nr. 6.

${ }^{18}$ Oskar KRAUSE und Karl KunZE, Die älteren Zunfturkunden der Stadt Greifswald. Teil 1, in: Pommersches Jahrbuch 1, 1900, S. 97-169: Dies., Die älteren Zunfturkunden der Stadt Greifswald. Teil 2, in: Pommersches Jahrbuch 2, 1901, S. 109-159.

${ }^{19}$ Zur Übersicht vgl. Theodor PYL. Dr. Heinrich Rubenows Leben und die Geschichte seiner Vorfahren (Pommersche Geschichtsdenkmäler Bd. 3), Greifswald 1870, S. XI-XXIII.

${ }^{20} \mathrm{Vgl}$. POECK, Das älteste Greifswalder Stadtbuch (wie Anm. 11), S. LXXV- LXXXI; dazu IGEL. Greifswalder und Greifswald um 1400 (wie Anm. 4), S. 229.

${ }^{21}$ StAG Rep. 3 Nr. 34.

${ }^{22}$ Vgl. Heiko SCHÄFER, Früher Holz- und Steinbau in der Hansestadt Greifswald, in: Lübecker Kolloquium zur Stadtarchäologie im Hanseraum III: Der Hausbau, hg. von Manfred GLÄSER, Lübeck 2001, S. 421 -431: DERS.. Ergebnisse (wie Anm. 9).

${ }^{23}$ Zur Übersicht: Jens-Christian HoLST, Hausforschung in Greifswald. Versuch eines Überblicks, in: Jahrbuch für Hausforschung 49: Historischer Hausbau zwischen Elbe und Oder, Marburg 2002. S. 287-322: Felix SCHÖNROCK. Zur Inventarisation der Altstadthäuser und den Aussagemöglichkeiten der Schriftquellen des 17.-19. Jahrhunderts in Greifswald, in: Bauforschung und Archäologie. Stadt- und Siedlungsentwicklung im Spiegel der Baustrukturen. hg. von Dirk SchumanN. Berlin 2000, S. 185-201; für die Einführung in die Greifswalder Baugeschichte habe ich André Lutze, Torsten Rütz und Felix Schönrock. alle Greifswald, herzlich zu danken.

${ }^{24} \mathrm{Vgl}$. IGEL, Greifswalder und Greifswald um 1400 (wie Anm. 4), S. 122-140. 
blöcken. ${ }^{25}$ Hinzu kommt, dass mit der schwedischen Matrikel von 1707 für Greifswald eines der ältesten Grundstückskataster in Deutschland vorliegt. ${ }^{26}$

\section{Osnabrück}

Das spätmittelalterliche Osnabrück dürfte im 15. Jahrhundert mit 8000 bis 10000 Einwohnern etwa über die doppelte Kopfzahl Greifswalds verfügt haben. ${ }^{27}$ Unter Einbeziehung der Vorstädte am Fuß von Wester- und Gertrudenberg dehnte sich die Stadt seit dem ausgehenden 14. Jahrhundert über eine Fläche von gut 130 ha aus und übertraf damit deutlich die übrigen westfälischen Städte (Abb. 2). ${ }^{28}$ Auch in Osnabrück kam es zu einer Vereinigung von Alt- und Neustadt, allerdings schlossen sich diese 1307 nicht auf Veranlassung des Stadtherrn, sondern durch einen Vertrag zwischen beiden Stadträten zusammen. ${ }^{29}$ Beide blieben in den internen Angelegenheiten weitgehend autonome Städte, besaßen je einen eigenen Rat, ein eigenes Rathaus und einen eigenen Markt. So ließ der Neustädter Rat ab 1348 ein Rathaus mit Kaufhaus, Fleischscharren und Brotbänken auf dem Gebiet der Johannisfreiheit errichten. ${ }^{30}$ Neben den Dom, Johannisstift und die beiden Pfarrkirchen traten mit dem im 11. und 12. Jahrhundert gegründeten und um 1300 in den zweiten Befestigungsring integrierten Benediktinerinnenkloster auf dem Gertrudenberg, ${ }^{31}$ den im 13. Jahrhundert entstandenen Klöstern der Franziskaner, Augustiner und Dominikaner, der Kommende des Deutschen Ordens aus der ersten Hälfte des 14. Jahrhunderts sowie den in der zweiten Hälfte des 15. Jahrhunderts

\footnotetext{
${ }^{25}$ Vgl. Jörg ANSORGE. Karsten IGEL, Heiko SCHÄFER und Julian WIETHOLD, Ein Holzschacht aus der Baderstraße I in Greifswald. Aus der materiellen Alltagskultur der sozialen Oberschicht einer Hansestadt in der 2. Hälfte des 14. Jahrhunderts, in: Bodendenkmalpflege in Mecklenburg-Vorpommern. Jahrbuch 2002 (2003), Bd. 50. S. 119-157; Renate SAMARITER, Karsten IGEL und Heiko SCHÄFER, Ein cuir-bouilli-Becher und die Patrizierfamilie Lowe. Archäologische und historische Forschungen zu einem Quartier am Greifswalder Hafen. Jahrhunderts, in: Bodendenkmalpflege in Mecklenburg-Vorpommern. Jahrbuch 2002 (2003), Bd. 50, S. 173-206.

${ }^{26}$ Die Schwedische Landesaufnahme von Vorpommern 1692-1709. Karten und Texte. Städte Bd. 2: Greifswald, hg. von der historischen Kommission für Pommern und dem Landesarchiv Greifswald in Verbindung mit der Gesellschaft für pommersche Geschichte, Altertumskunde und Kunst e. V., Greifswald 2002.

${ }^{27}$ Vgl. Karsten IGEL, Quellen zur Einwohnerzahl und Sozialstruktur des spätmittelalterlichen Osnabrücks, in: OsnMitt. 106, 2001, S. 28 i-287.

${ }^{28}$ Vgl. Karsten IGEL, Zentren der Stadt. Überlegungen zu Stadtgestalt und Topographie des spätmittelalterlichen Osnabrücks, in: OsnMitt. 106, 2001, S. 11-47, hier S. 16-18.

${ }^{29}$ Osnabrücker Urkundenbuch Bd. 6, Nr. 62 - 1307 März 10.

${ }^{30}$ Ebd.. Nr. 527 - 1348 Januar 26.

${ }^{31} \mathrm{Vgl}$. Karsten IGEL, Von der vorkommunalen zur kommunalen Stadt. Zur frühen Stadtentwicklung Osnabrücks vom 11. bis zum 13. Jahrhundert, in: OsnMitt. 109, 2004 (im Druck).
} 


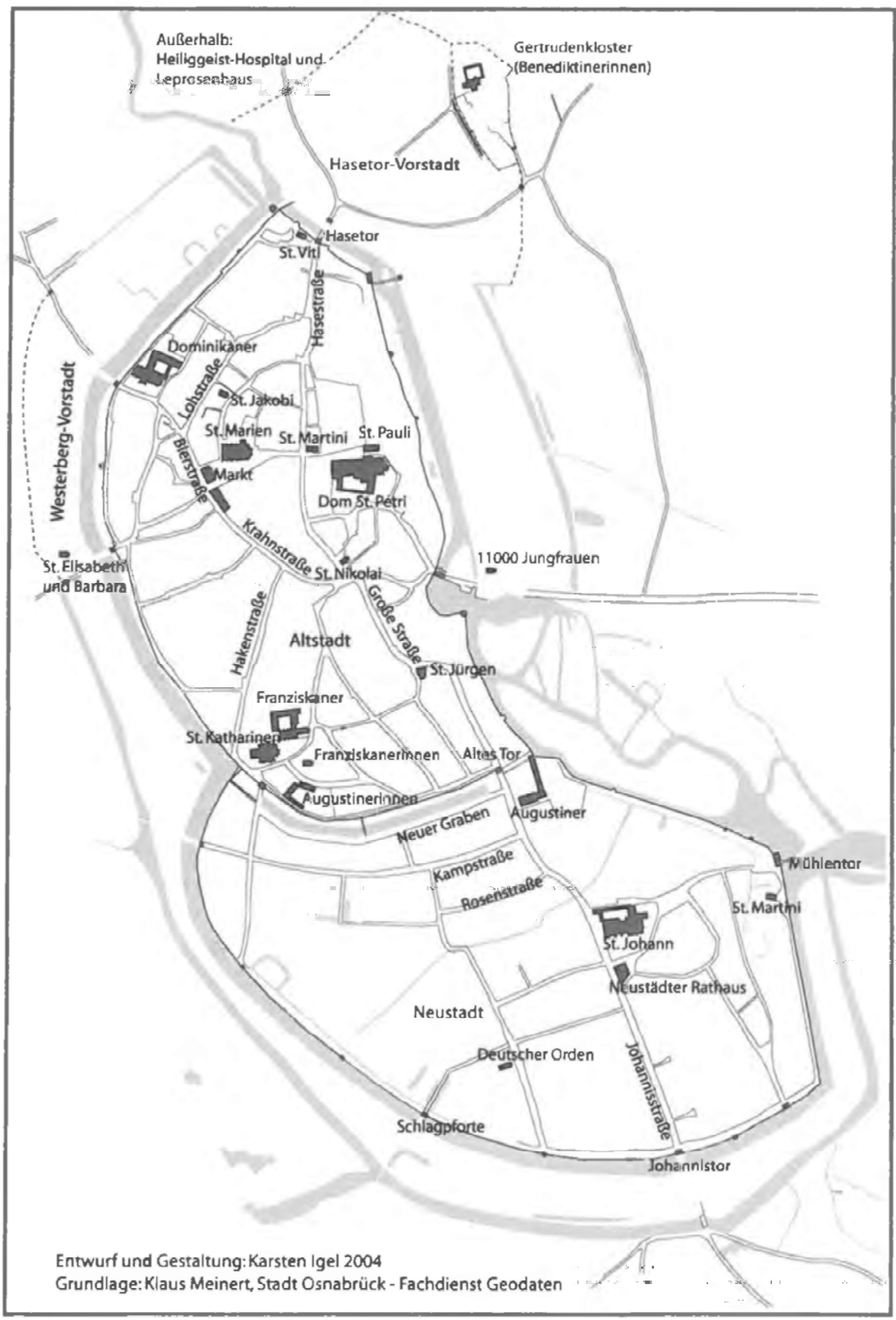

Abb. 2: Osnabrück, geistliche Einrichtungen um 1500 
aus Beginenhäusern hervorgegangenen Klöstern der Augustinerinnen und Franziskanerinnen immerhin sieben Ordensniederlassungen. Hinzu kamen fünf Beginenhäuser, die noch am Ende des Mittelalters bestanden, zwölf weitere Kapellen, ${ }^{32}$ die unter anderem zu vier größeren Hospitälern vor den Stadttoren gehörten, zwei Pilgergasthäuser sowie zahlreiche größere und kleinere Armenhäuser. ${ }^{33}$ Dank Domkirche und Johannisstift sowie der zahlreichen Klöster war Osnabrück durchsetzt mit zum Teil großflächigen Immunitätsbezirken (allein die Domsfreiheit nahm gut ein Viertel der Altstadt ein). Die bürgerliche und die geistliche Seite standen so in einem langwierigen Konflikt um steuerliche und rechtliche Hoheit, waren zugleich aber auch personell eng miteinander verbunden, konkurrierten um Beteiligung an der Landesherrschaft im Stift, standen gegen oder Seite an Seite mit dem Bischof. ${ }^{34}$

Das heutige Rathaus der Altstadt ist bereits das dritte Gebäude in dieser Funktion, ein erstes wurde 1244 erwähnt, das zweite nach einem vor 1254 wütenden Stadtbrand errichtet, um dann 1487 dem Neubau des heutigen weichen zu müssen. Erst zusammen mit diesem entstand auch der dreieckige, von Rathaus, Marienkirche und Treppengiebelhäusern umrahmte Marktplatz als räumlicher Gegenpol zur Domsfreiheit. ${ }^{35}$

Die schriftliche Überlieferung ist für Osnabrück seit dem 14. Jahrhundert und besonders seit der Mitte des 15. Jahrhunderts ausgesprochen dicht und nur mit Schwierigkeiten zu überschauen. Neben einer umfangreichen urkundlichen Überlieferung, die zum größten Teil Grundstücks- und Rentengeschäfte verschiedener Formen betrifft, stehen Stadtrechnungen mit ersten Fragmenten aus dem 13. und 14. Jahrhundert, die dann ab der Mitte des 15. Jahrhundert in fast lückenloser Folge bis in die Neuzeit reichen. Erhalten sind nicht nur die Hauptrechnungen von Alt- und Neustadt, sondern auch Vorabrechnungen zu verschiedenen Segmenten wie Lohnrechnungen, verschiedene Akziserechnungen usw. ${ }^{3 \hbar}$ Umfangreiche Renten-

\footnotetext{
${ }^{32} \mathrm{Vgl}$. IGEL, Zentren (wie Anm. 28), S. 21-23.

${ }^{33} \mathrm{Vgl}$. Hermann QuECKENSTEDT, Die Armen und die Toten. Sozialfürsorge und Totengedenken im spätmittelalterlich-frühneuzeitlichen Osnabrück (Kulturregion Osnabrück 8), Osnabrück 1997. - Zur Lage in der Stadt, IGEL, Zentren (wie Anm. 28), S. 39-42.

${ }^{34} \mathrm{Vgl}$. Hermann RotherT, Geschichte der Stadt Osnabrück im Mittelalter, in: OsnMitt. 58, 1938, S. 1-435, hier S. 60-69; Bernd-Ulrich Hergemöller, „Pfaffenkriege“ im spätmittelalterlichen Hanseraum. Quellen und Studien zu Braunschweig. Osnabrück, Lüneburg und Rostock. Teil I (Städteforschung C/2/I), Köln/Wien 1998, S. 83-1111.

${ }^{35} \mathrm{Vgl}$. Karsten IGEL, Von der Straße zum Platz. Der Osnabrücker Markt - ein Stadt-Raum im Wandel, in: Mercatum et Monetam. 1000 Jahre Markt-, Münz- und Zollrecht in Osnabrück (Schriften zur Archäologie des Osnabrücker Landes Bd. III), hg. von Wolfgang SCHLÜTER, Bramsche 2002, S. 171-196. hier S. 178-183.

${ }^{36}$ Ilse EBERHARDT, Van des stades wegene utgegeven unde betalt. Städtischer Alltag im Spiegel der Stadtrechnungen von Osnabrück 1459-1519 (Osnabrücker Geschichtsquellen
} 
und Einnahmeregister liegen für das Johannisstift ${ }^{37}$ und das Gertrudenbergkloster ${ }^{38}$ aus dem 15. Jahrhundert vor, städtische Einnahme- und Rentenverzeichnisse im Osnabrücker Stadtbuch seit dem 14. Jahrhundert. ${ }^{39}$ Die Liste ließe sich ohne Schwierigkeiten gerade um prosopographisch wertvolle Quellen weiter ausdehnen. Genannt seien hier aber noch das 1377 einsetzende Bürgerbuch der Neustadt (bis 1717) ${ }^{40}$ und das Altstädter Gegenstück, das von 1454 bis 1591 reicht. ${ }^{41}$ Letzteres enthält zudem ab 1448 fast lückenlos die jährlichen Listen der städtischen Schützen. Schlechter ist es dagegen um Steuerverzeichnisse bestellt: Die einzige bislang aufgefundene vollständige Vermögenssteuer ist die sogenannte „Gütliche Kontribution" von 1487, die aber (für Steuerverzeichnisse nicht untypisch) mit einigen Problemen behaftet ist. ${ }^{42}$ Ein bemerkenswertes, aber leider unvollständiges Verzeichnis für die Leischaften der Altstadt von 1463 gliedert sich in einen als Kopfsteuer von jedem erwachsenen Haushaltsmitglied erhobenen Vorschoß und eine anschließende Vermögenssteuer auf. Beide Teile sind leider nur für die Butenburg erhalten, für Hase- und Marktleischaft der Vorschoß und für die Johannisleischaft nur die Vermögenssteuer. ${ }^{43}$ Alle steuerpflichtigen Personen bzw. Haushaltsvorstände aus Alt- und Neustadt erfasst ein Vorschoßregister von $1447.4^{44}$ Hintergrund dieser scheinbar dünnen Überlieferung sind aber nicht fehlende Quellen, sondern die fehlende zeitgenössische direkte Besteuerung. Eine Durchsicht der Einnahmen in den Altstädter Stadtrechnungen zwischen 1459 und $1512^{45}$ zeigte Erträge aus einem Vorschoß nur für 1459 und 1461, dann erst wieder einen Vorschoß 1486 und die „Gütlichen Kon-

und Forschungen 37), Osnabrück 1996, S. 22-30; diese Edition und Auswertung bezieht sich auf die Ausgaben der Altstadt, die auch die gesamtstädtischen Aufgaben umfassen, die Einnahmen werden für drei Jahre (1459, 1489 und 1519) exemplarisch vorgestellt. Stadtrechnungen der Neustadt liegen ab 1441 vor, StAOs Dep. 3b II Nr. 25 und Dep. 3b IV Nr. 1140.

${ }^{37}$ Staatsarchiv Osnabrück (StAOs) Rep. 100 Abschnitt 335 Nr. 6.

${ }^{38}$ StAOs Rep. 2 Nr. 164.

${ }^{39}$ Das älteste Stadtbuch von Osnabrück, hg. von Erich FINK (Osnabrücker Geschichtsquellen 4), Osnabrïck 1927.

${ }^{40}$ StAOs Dep. 3b IV Nr. 369.

${ }^{41}$ StAOs Dep. 3b IV Nr. 354.

42 Jürgen Bонмвасн, Die „Gütliche Kontribution“"von 1487, in: OsnMitt. 79. 1972, S. 37-54; kritisch dazu IGEL, Quellen, Anm. 27, S. 283-287.

${ }^{43}$ StAOs Dep. 3b II Nr. 538. Nr. 539, Nr. 540; dazu Karsten Igel, Auf der Spur des Stadt-Raums. Osnabrücker Quellen zur Raumsoziologie der mittelalterlichen Stadt, in: Vom Großsteingrab zur Domburg. Forschungsorientierte Denkmalpflege im Osnabrücker Land. Festschrift für Wolfgang Schlüter zum 65. Geburtstag (Internationale Archäologie: Studia honoraria 19), hg. von Axel FriederichS, Karsten IGEL und Bodo ZEHM, Rahden (Westf.) 2002, S. 139-160, hier S. 140-147.

${ }^{44}$ StAOs Dep. 3b II Nr. 541.

${ }^{45}$ StAOs Dep. 3b II Nr. 1 und Nr. 2 - nicht erhalten sind aus diesem Zeitraum die Jahrgänge 1460, 1462-1464, 1469, 1491, 1498, 1500, 1501, 1504, 1506, 1507 und 1510. 
tribution" 1487, wobei Restbeträge aus dieser Vermögenssteuer noch 1488 und 1489 eingenommen wurden. In der Zwischenzeit wurde nur 1480 und 1481 jeweils eine geringe Schatzung von einem Pfennig je Haushalt erhoben, deren Einnahmen der Erhaltung der städtischen Privilegien dienen sollten. ${ }^{46}$ Die Rechnungen aus dem Jahr der Altstädter Schatzung von 1463 sind leider nicht erhalten. Demnach erfolgte zwischen 1463 und 1486 weder ein Vorschoß noch eine Vermögenssteuer. Weitere Schatzungen folgten dann 1495 und 1496, letztere wurde ausdrücklich, wie dann auch noch einmal 1503, zur Bestreitung der Kosten des Rathausbaus erhoben.

Von den spätmittelalterlichen Stadtrechnungen abgeseben, ${ }^{47}$ ist ein Großteil dieser Quellen bislang kaum erschlossen und so bestehen auch erst Ansätze einer Auswertung. ${ }^{48}$ Die archäologischen Untersuchungen sind für die Altstadt, insbesondere Dom und Markt, recht dicht, für die Neustadt allerdings eher dünn gesät. Die bisherigen Auswertungen konzentrieren sich vor allem auf die Entstehungsgeschichte der Stadt bis zum 13. Jahrhundert sowie auf den Bereich um Dom und Markt. ${ }^{49}$ Daneben liegt ein erster Inventarband der archäologischen Denkmale vor. ${ }^{50}$ Bauhistorisch sind für das mittelalterliche Osnabrück die ehemals sehr zahlreichen Steinwerke von Bedeutung (auch im Blick auf ihre räumliche Verteilung). Nach einer älteren Untersuchung und einer ersten Neubewertung durch die städtische Denkmalpflege ist inzwischen ein umfassendes Kataster geplant. ${ }^{51}$

${ }^{46}$ Das älteste Stadtbuch von Osnabrück (wie Anm. 39), S. 135.

${ }^{47}$ Ererhardt, Städtischer Alltag (wie Anm. 36).

${ }^{48} \mathrm{Vgl}$. IGEL, Auf der Spur des Stadt-Raums (wie Anm. 43).

${ }^{49} \mathrm{Vgl}$. Wolfgang SCHLÜTER. Osnabrück in karolingisch-ottonischer Zeit, in: 799. Kunst und Kultur der Karolingerzeit. Karl der Große und Papst Leo III. in Paderborn. Beiträge zum Katalog der Ausstellung Paderborn 1999, hg. von Christoph STIEGEMANN und Matthias WEMHOFF, Mainz 1999, S. 394-400; DERS., Die Ausgrabungen in der Marienkirche und auf dem Marktplatz, in: Die Marienkirche in Osnabrück. Ergebnisse archäologischer, bau- und kunsthistorischer Untersuchungen, hg. von Karl-Georg KASTER und Wolfgang SCHLÜTER, Bramsche 2001, S. 19-125; DERS., Archäologische Zeugnisse zur Entstehung der Stadt Osnabrück, in: Stadtarchäologie in Norddeutschland westlich der Elbe, hg. von Heiko STEUER und Gerd BIEGEL (Zeitschrift für Archäologie des Mittelalters, Beiheft 14), Bonn 2002, S. 37-103; IGEL, Von der vorkommunalen zur kommunalen Stadt (wie Anm. 31).

${ }^{50}$ Archäologische Denkmale in der kreisfreien Stadt und im Landkreis Osnabrück, hg. von Friedrich-Wilhelm WULF und Wolfgang SCHLÜTER (Materialhefte zur Ur- und Frühgeschichte Niedersachsen B/2), Hannover 2000

${ }^{51}$ Adolf IDE. Die Steinwerke der Stadt Osnabrück. Ein Beitrag zur Erforschung der Bauund Wohnkultur alter niedersächsischer Städte, Osnabrück 1939; Bruno SwiTALLA, Die Osnabrïicker Steinwerke, in: Vom Grosssteingrab zur Domburg (wie Anm. 43), S. 133-137; eine neue Aufnahme wird durch Mike Hurst, Osnabrück, vorbereitet; zur Baugeschichte Osnabrücks vgl. auch Roswitha POPPE, Das Osnabrücker Bürgerhaus, Oldenburg 1944; zur räumlichen Verteilung der Steinwerke auch IGEL, Auf der Spur des Stadt-Raums (wie Anm. 43), S. $156 \mathrm{f}$. 


\section{Die Elemente der Sozialtopographie}

\subsection{Vermögensbestimmung und ihre Bewertung}

Vor dem Hintergrund dieser beiden Städte soll nun eingehender auf die Möglichkeiten und Schwierigkeiten sozialtopographischer Forschung eingegangen werden. Von Bedeutung sind hier die Fragen nach der Vermögensbestimmung (Höhe, Zusammensetzung, Art der Besteuerung), der sozialen Bewertung des Vermögens und damit die Einordnung in eine soziale Gruppe oder Schicht und die Frage nach der räumlichen Zuordnung der Einwohner innerhalb der Stadt und der Gerwauigkert, mit der dies geschehen kann. ${ }^{52}$ Diese Punkte markieren zugleich auch die Grenzen, an die Untersuchungen für fast jede Stadt quellenbedingt stoßen müssen. Für Greifswald und Osnabrück wurde bereits auf die nur wenigen erhaltenen bzw. erstellten Steuerverzeichnisse hingewiesen. Auch für die meisten anderen Städte muss festgehalten werden, dass weitgehend geschlossene Reihen von Steuerverzeichnissen, wie sie für Rostock seit dem ausgehenden 14. Jahrhundert vorliegen, ${ }^{53}$ eher selten sind. Aber auch dann ergeben sich weitere Probleme: nicht immer ist die Bemessungsgrundlage klar, zum Teil wurden für verschiedene Vermögensformen unterschiedliche Steuersätze veranlagt, aber nur der Gesamtbetrag genannt, so dass aus diesem nicht auf das Vermögen geschlossen werden kann. Schwer zu klären ist häufig auch, ob jemand keine Steuern zahlte, weil er arm oder aber aus anderen Gründen steuerbefreit war, ebenso, ob letztere in den Verzeichnissen mit aufgeführt wurden oder gleich unberücksichtigt blieben. ${ }^{54}$ Diese Steuerverzeichnissen grundsätzlich immanenten Schwierigkeiten hat Rudolf Biederstedt am Beispiel von verschiedenen Registern aus dem südwestlichen Ostseeraum in einem bereits 1966_verfassten Aufsatz, der

\footnotetext{
${ }^{52}$ Vgl. Hans-Christoph Rublack, Probleme der Sozialtopographie der Stadt im Mittelalter und in der frühen Neuzeit, in: Voraussetzungen und Methoden geschichtlicher Städteforschung, hg. von Wilfried EHBRECHT (Städteforschung A/7). Köln/Wien 1979. S. 177-193; Dietrich DENECKE, Sozialtopographische und sozialräumliche Gliederung der spätmittelalterlichen Stadt. Problemstellungen, Methoden und Betrachtungsweisen der historischen Wirtschafts- und Sozialgeographie, in: Über Bürger. Stadt und städtische Literatur (wie Anm. 1). S. 161-202: Die Sozialstruktur und Sozialtopographie der vorindustriellen Stadt (wie Anm. $5)$.

${ }^{53}$ Zur Übersicht vgl. Johannes SCHILDHAUER, Die Sozialstruktur der Hansestadt Rostock von 1378-1569, in: Hansische Studien 4, Berlin 1961. S. 342.

${ }^{54}$ Zur Frage der Vollständigkeit vgl. Ulf DIRLMEIER, Untersuchungen zu Einkommensverhältnissen und Lebenshaltungskosten in oberdeutschen Städten des Spätmittelalters (Mitte 14. bis Anfang 16. Jahrhundert) (Abhandlungen der Heidelberger Akademie der Wisšenschaften. Philosophisch-Historische Klasse, Jg. 1978, Abh. I), Heidelberg 1978, S. 492-503.
} 
dank der Interventionen des darin kritisierten Johannes Schildhauers aber erst 1993 erscheinen konnte, sehr anschaulich dargelegt. ${ }^{55}$

Lässt sich das Vermögen aus der Steuerleistung bestimmen, stellt sich die Frage, welche Aussagen daraus über die soziale Schichtung der Stadtbevölkerung getroffen werden können. ${ }^{56}$ Dies führt in den meisten Fällen zu einem Schichtungsmodell, das von Heinrich Rüthing ironisch treffend mit „Societas est omnis divisa in partes tres: Oberschicht, Mittelschicht und Unterschicht" beschrieben wurde..$^{57}$ Aūch wên den Schichten, wie von Ellermeyer gefordert, sich möglichst an zeitgenössischen Kriterien wie Hochzeitsordnungen etc. orientieren, ${ }^{58}$ stellt sich die Frage, ob ein solches Modell nicht doch ein wenig zu vereinfachend ist und einer Gesellschaft rückwirkend ein eher modernes Bild aufdrückt. Gerade wenn nur vereinzelte Steuerverzeichnisse vorliegen, besteht die Gefahr, einzelne Personen in ein zu starres Raster einzuordnen und dabei die sozialen Auf- und Abstiegsmöglichkeiten zu überdecken bzw. zu übersehen. ${ }^{59}$ Dies ist aber die eigentlich interessante Frage an die soziale Struktur der städtischen Gesellschaft und ihr Funktionieren über einen längeren Zeitraum. Gleiches gilt auch für die Sozialtopographie einer Stadt: Es ist zwar schön zu wissen, wie sie sich zu einem bestimmten Zeitpunkt darstellte, wirklich interessant wird es aber, wenn sich zeigen lässt, ob dies einen längerfristigen Zustand widerspiegelt oder sich ein Wandel beobachten lässt, der in Zusammenhang mit gesellschaftlichen Veränderungen gebracht werden kann. Auf die Einzelperson bezogen, ist die wesentliche Frage, wo sie zu welchem Zeitpunkt wohnte und wie sich die Motivation zu einem Umzug innerhalb der Stadt begründen lässt - diese Frage kann

\footnotetext{
${ }^{55} \mathrm{Vgl}$. Rudolf BIEDERSTEDT, Frühneuzeitliche Steuerregister als sozialstatistische Quelle; in: BaltStud. 79. 1993, S. 7-24; vor allem auch die Vorbemerkungen Biederstedts zu der Geschichte dieses Beitrages, der so auch ein interessantes Stück Wissenschaftsgeschichte darstellt; zu den Problemen der Auswertung vgl. auch Erik FüGEDI, Steuerlisten, Vermögen und soziale Gruppen in mittelalterlichen Städten, in: Städtische Gesellschaft und Reformation, hg. von Ingrid BÁTORI (Spätmittelalter und Frühe Neuzeit, Tübinger Beiträge zur Gesehiehtsforsehung Bd. 12), Stuttgart 1980, S. 58-96; Erdmann WEYRAUCH, Zur Auswertung von Steuerbüchern mit quantifizierenden Methoden. in: Festgabe für Ernst Walter Zeeden zum 60. Geburtstag, hg. von Horst RABE. Hansgeorg MOLITOR und Hans-Christoph RuBLACK (Reformationsgeschichtliche Studien und Texte, Supplementband 2), Münster 1976, S. 97-127: RÜTHING, Höxter um 1500 (wie Anm. 5), S. 26-31; STEEnwEG, Göttingen um 1400 (wie Anm. 2), S. 157-173; Sсносн, Die Bevölkerung der Stadt St. Gallen (wie Anm. 5), S. 41-54.

${ }^{56}$ Als grundsätzliche Übersicht mit oberdeutschen Beispielen vgl. DIRLMEIER, Untersuchungen zu Einkommensverhältnissen und Lebenshaltungskosten (wie Anm. 54), S. 503-531.

${ }^{57}$ Vgl. Rüthing, Höxter um 1500. (wie Anm. 5), S. 15.

${ }^{58} \mathrm{Vgl}$. Elu.erMEYER, Sozialgruppen (wie Anm. 1), S. 235-27l.

${ }^{59} \mathrm{Vgl}$. dazu unten das Beispiel der Greifswalder Familie Slupwachter.
} 
vom Individuum ausgehend auch auf die soziale Gruppe und ihre Mitglieder erweitert werden.

\subsection{Einkommen und Vermögen}

Was besagt das Nichtzahlen von Steuern oder ein nur geringer Steuersatz über die Lebensverhältnisse des Einzelnen? Auch jene Einwohner der Stadt, die keine Steuern zahlten, da sie über kein zu versteuerndes Vermögen verfügten, waren nicht automatisch und in gleichem Maße von Armut betroffen, ohne hier überhaupt erörtern zu wollen, was denn unter Armut zu verstehen ist bzw. wie sie sich in den Quellen sicher fassen lässt. ${ }^{60}$ Da das laufende Einkommen, das zugleich wieder verbraucht wurde, nicht zur Veranlagung kam, konnten Mitglieder dieser Gruppe durchaus einen ausreichenden Lebensstandard aufweisen - waren allerdings bei Einkommensausfall von schnellerer Verarmung bedroht. Solch ein „steuerfreies Existenzminimum“, um diesen modernen Begriff als Überspitzung zu verwenden, hing zudem von der Haushaltsgröße ab, war bei einer Einzelperson natürlich niedriger als bei einer Familie. Überschritt das Einkommen den zum alltäglichen Leben notwendigen Betrag, wird eine gewisse Ansammlung von Vermögen als Vorsorge für Notzeiten oder das Alter zu erwarten sein. So dürfte an der Grenze zwischen Steuerzahlern und Nichtsteuerzahlern in der Tat wohl so etwas wie ein „Existenzminimum" zu fassen sein. Unterhalb dieser Grenze befanden sich natürlich auch viele, die beständig über ein zu geringes Einkommen verfügten, auf Almosen angewiesen waren, in unwürdigen Zuständen leben mussten. Allerđings erscheint ein wesentlicher Teil der eigentlichen Unterschicht, die Knechte, Mägde und Gesellen, die als unselbständige Arbeitskräfte mit in den Haushalten lebten, so gut wie gar nicht in den Quellen. Das schon erwähnte und in diesem Zusammenhang herausragende Osnabrücker Vorschoßregister von 1463 weist für die 428 Haushalte der Altstädter Leischaft Butenburg immerhin 222 Mitglieder dieser Gruppe auf. In einzelnen Straßen lag der Durchschnitt sogar bei mehr als einer Person pro Haushalt. Der Vergleich mit der Hauptschatzung für diese Leischaft liefert einen weiteren bemerkenswerten Befund: es finden sich nicht wenige Haushalte, die über mehrere Knechte und/oder Mägde verfügten, zugleich aber am unteren Rand der Steuerskala rangierten bzw. gar nichts zahlten. ${ }^{61}$ Ist nun jemand als arm oder Mitglied der Unterschicht einzustufen, wenn er keine Steuer zahlt, aber über eine Magd und einen Gesellen oder

\footnotetext{
${ }^{60}$ Vgl. auch ScHOCH. Die Bevölkerung der Stadt St. Gallen (wie Anm. 5), S. 71-79.

${ }^{61}$ StAOs Dep. $3 b$ II Nr. 539; vgl. dazu Igel, Auf der Spur des Stadt-Raums (wie Anm. 43), S. $146 \mathrm{f}$.
} 
Knecht in seinem Haushalt verfügt? Die Schicht der Dienstboten war zwar wirtschaftlich abhängig und verfügte nur über geringes Einkommen, andererseits lebten sie mit im Haushalt und hatten so Unterkunft und Nahrung, ohne diese aus ihrem Einkommen bestreiten zu müssen.

Die reine Besteuerung des Vermögens führt aber auch für die wohlhabenderen Gruppen zu einer Verzerrung des Bildes, denn die größeren finanziellen Aufwendungen für einen höheren Lebensstandard blieben ja unberücksichtigt - es sei denn, sie entstammten aus Renten- oder Immobilienvermögen, wovon gleich noch zu sprechen sein wird. Hinzu kommt noch die Frage, welcher Vermögensanteil unbesteuert blieb. So legte eine Verordnung des Osnabrücker Rates aus der Mitte des 15. Jahrhunderts fest, dass neben dem Vorschoß von allen Gütern in und außerhalb der Stadt ein Pfennig für jede Mark $(0,69 \%)$ zu zahlen sei. Unbesteuert blieben allerdings Kleider, Kleinodien, Pferde, Harnisch, Hausrat und der Hausbedarf an Getreide bis zur nächsten Ernte. ${ }^{62}$ Der Besitz von Pferd und Harnisch lag im Sicherheitsinteresse der Stadt, ebenso ein ausreichender Getreidevorrat und auch die Steuerbefreiung der notwendigen Haushaltsgüter ist naheliegend. Freilich können sich hinter Kleinodien und Hausrat größere Vermögenswerte in Form von Silber verbergen und auch der Wert der Bekleidung war wohl nicht ganz einheitlich. Gleiches lässt sich für Stralsund in den 1530er Jahren belegen. ${ }^{63}$

Einen Unterschied machte auch die Herkunft des Einkommens. Denn hinter Einnahmen aus Renten- und Immobilienbesitz stand ja ein Vermögenswert, der zur Steuer herangezogen wurde, bei Einnahmen aus Handel oder Handwerk galt dies nur für den Teil, der zur Vermögensbildung übrig blieb. Dies bedeutet aber, dass jemand, der über ein sicheres Renteneinkommen verfügte, steuerlich weitaus stärker belastet wurde als jemand, der das gleiche Einkommen aus handwerklicher oder kaufmännischer Tätigkeit erzielte, dafür aber von den Risiken und Schwankungen des Marktes abhängig war. Ein aus der gezahlten Steuer errechnetes Vermögen lässt somit aber noch nicht notwendig auf den Lebensstandard schließen. Natürlich bedurfte auch eine gewerbliche Tätigkeit eines ausreichenden Kapitals, das als Vermögen zu versteuern war, hier ist also die zu erzielende Rendite im Vergleich zum Rentenzins von Interesse. Der Gewinn dürfte sich wiederum unterschieden haben, je nachdem ob der Schwerpunkt im Groß- oder Detailhandel lag oder beides in ciner Hand miteinander verbunden war. Solange (wiedereinlösbare) Renten aber auch zur Kapitalbeschaffung für Handel dienten, ist eine durchschnittliche Ren-

\footnotetext{
${ }^{62}$ Vgl. Rothert, Geschichte (wie Anm. 34), S. 97.

${ }^{63}$ Vgl. BiEDERSTEDT, Frühneuzeitliche Steuerregister (wie Anm. 55), S. 10.
} 
dite zu erwarten, die über deren durchschnittlichem Zinsfuß lag. Noch einmal anders lag die Sache für den Handwerker, dessen wesentliches Kapital seine Fähigkeiten und die Arbeitsleistung seiner Hände waren. ${ }^{64}$

Nehmen wir zum Beispiel den Osnabrücker Tagelöhner Johann Francke, der nach den für 1477 und 1480 erhaltenen Lohnrechnungen als Handlanger bei städtischen Bauarbeiten mitwirkte. ${ }^{65}$ Bei einer Tätigkeit von 162 bzw. 166 Tagen im Jahr verdiente er etwa 1300 Pfennige. Dies muss freilich nicht sein gesamtes Einkommen gewesen sein, da sich nach Abzug der Sonn- und Feiertage für Osnabrück im 15. Jahrhundert eine mögliche Jahresarbeitszeit von 260 bis 265 Tagen errechnet, ${ }^{66}$ es blieben ihm also noch gut 100 weitere Tage, an denen er bei gleichem Tagelohn theoretisch weitere 800 Pfennige verdienen und so auf ein Jahreseinkommen von rund 2100 Pfennigen kommen konnte. Um ein vergleichbares Einkommen aus Renten zu erhalten, war bei Rentensätzen zwischen $5 \%$ und $8 \%$ ein Kapital von 182 bis 292 Mark notwendig. ${ }^{67}$ Nach dem einzigen für Osnabrück für das 15. Jahrhundert überlieferten Steuersatz von einem Pfennig je Mark Vermögen, wäre ein solches Rentenkapital mit 182 bis 292 Pfennigen zu versteuern gewesen. Wenn Johann Francke hingegen sein gesamtes mit seinen Händen erarbeitetes Einkommen verbrauchte, war er nur den üblichen Vorschoß von 12 Pfennigen schuldig! Dies sind zwar sicherlich Extrembeispiele, aber sie verdeutlichen die grundsätzliche Problematik. Allerdings war auch Johann Francke nicht ganz unvermögend, zur Gütlichen Kontribution steuerte er 1487 immerhin 72 Pfennige bei. ${ }^{68}$ Da bei dieser Sondersteuer der übliche Steuersatz eher unterschritten wurde, ${ }^{69}$ entsprach dies einem Vermögen von wenigstens 72 Mark plus Hausrat usw. Zudem besaß der Tagelöhner Johann Francke schon 1480 ein eigenes Haus in der Großen Straße zwischen Nikolaiort und der Georgskapelle, aus dem er dem Gertrudenkloster jährlich einen rheinischen Gul-

\footnotetext{
${ }^{6+} \mathrm{Zu}$ den Einkommen vgl. DiRLMEIER, Untersuchungen zu Einkommensverhältnissen und Lebenshaltungskosten (wie Anm. 54), S. 99-129.

${ }^{65} \mathrm{Vgl}$. Ilse EBERHARDT, Arbeit, Lohn und Lebenshaltungskosten von Bauhandwerkern im spätmittelalterlichen Osnabrück, in OsnMitt. 103, 1998, S. 11-42, hier S. 36, und DIES., Städtischer Alltag (wie Anm. 36), S. 92-98; zu den Einkommen von Tagelöhnern vgl. auch DIRLMEIER, Untersuchungen zu Einkommensverhältnissen und Lebenshaltungskosten (wie Anm. 54), S. 129-223; zu denen von Lohnarbeitern und Handwerksgesellen vgl. Knut SCHULZ, Handwerksgesellen und Lohnarbeiter. Untersuchungen zur oberrheinischen und oberdeutschen Stadtgeschichte des 14. bis 17. Jahrhunderts, Sigmaringen 1985, S. 325-400.

${ }^{66} \mathrm{Vgl}$. EbERHARDT Arbeit, Lohn und Lebenshaltungskosten (wie Anm. 65), S. 23.

${ }^{67} \mathrm{Zu}$ dên Rệntënsatzèn vgl. EBERHARDT. Städtischer Alltag (wie Anm. 36), S. 51.

${ }^{68} \mathrm{Vgl}$. ROTHERT, Geschichte (wie Anm. 34), S. 356; bei EBERHARDT. Arbeit, Lohn und Lebenshaltungskosten (wie Anm. 65), S. 36, hat sich mit den angegebenen 2 s ein Fehler eingeschlichen.

${ }^{69}$ Vgl. IGEL, Quellen (wie Anm. 27), S. 284f.
} 
den Rente zu zahlen hatte, ${ }^{70}$ nach dem Kurs des Jahres 1487 entsprach dies $11 / 2$ Mark. ${ }^{71}$ Angesichts der üblichen Rentensätze war das Haus also mit $18 \frac{3}{4}$ bis 30 Mark belastet, womit sich zugleich der Minimalwert des Hauses ergibt. ${ }^{72}$ Da es sich bei diesem Betrag um eine Hypothek handelte, zählte er natürlich auch nicht zum Vermögen, sondern der Wert des Hauses war um diesen vermindert. Dabei konnte ein Kauf auf Rentenbasis bei niedrigen Zinssätzen wirtschaftlich durchaus sinnvoll und für viele vielleicht auch die einzige Möglichkeit sein, ein Haus zu erwerben. Zudem verfügte Johann Francke über einen Garten, für den er dem Rat 147910 Schillinge schuldete. ${ }^{73}$ Nur, wie soll ein Johann Francke in ein soziales Ordnungsschema eingefügt werden? Er war Tagelöhner, aber auch Hausbesitzer und konnte zumindest ein wenig Geld zur Vermögensbildung zurücklegen - über weitere Einkommensquellen wie über seinen Lebensstandard wissen wir nichts. Dieser hing ja zudem davon ab, ob er alleinstehend war oder eine Familie ernähren musste. ${ }^{74} \mathrm{Ihn}$ als Tagelöhner einfach an den unteren Rand der Gesellschaft zu rücken, wäre jedenfalls nicht ganz zutreffend, sein Einkommen war zumindest höher als zur reinen Existenzerhaltung notwendig. Drei Gildemeister der Elf-Ämter, die als Vertreter der Handwerksämter im Großen Rat saßen, zahlten 1487 auch keine höhere Steuer als er. ${ }^{75}$

Der in der Gildewart wohnende Maurer Albert Bomwede arbeitete 1480 immerhin 220,5 Tage und damit den größten Teil seiner möglichen Arbeitszeit für die Stadt, was ihm einen Gesamtlohn von 2906 Pfennigen einbrachte. ${ }^{76}$ Sollte er auch noch die übrigen Tage für andere Auftraggeber gearbeitet haben, konnte er auf ein Jahreseinkommen von knapp 3500 Pfennigen kommen. Seine Einkommensverhältnisse können jedenfalls nicht schlecht gewesen sein, denn sieben Jahre später zahlte er zusammen mit seiner Mutter anlässlich der Gütlichen Kontribution 216 Pfennige, ${ }^{77}$ verfügte also über ein Vermögen von wenigstens 216 Mark. Damit lag er

\footnotetext{
${ }^{70}$ StAOs Rep. 2 Nr. 164, f 1r.

${ }^{71}$ Zum Verhältnis der Osnabrücker Mark zum Rheinischen Gulden vgl. EBERHARDT, Städtischer Alltag (wie Anm. 36), S. 21.

${ }^{72}$ Die Preise der 1487/88 für den Rathausbau angekauften Häuser lagen zwischen 33 rheinischen Gulden (44 Mark) und 144 Mark, vgl. EBERHARDT, Städtischer Alltag (wie Anm. 36), S. 98.

${ }^{73} \mathrm{Vgl}$. EBerhardT, Städtischer Alltag (wie Anm. 36), S. 316.

${ }^{74}$ Zur Frage der Lebenshaltungskosten bzw. zu den Möglichkeiten, diese zu ermitteln vgl. DIRLMEIER. Untersuchungen zu Einkommensverhältnissen und Lebenshaltungskosten (wie Anm. 54), S. 427-490; SCHUlz, Handwerksgesellen und Lohnarbeiter (wie Anm. 65), S. 400-442; EBERHARDT, Arbeit, Lohn und Lebenshaltungskosten (wie Anm. 65), S. 34-42.

${ }^{75} \mathrm{Vgl}$. ROTHERT, Geschichte (wie Anm. 34), S. $345 \mathrm{f}$.

${ }^{76}$ Vgl. EberhardT, Arbeit, Lohn und Lebenshaltungskosten (wie Anm. 65), S. 36.

${ }^{77}$ Vgl. ROTHERT, Geschichte (wie Anm. 34), S. 363.
} 
aber um gut $50 \%$ über dem durchschnittlichen Steuerbetrag von 145,9 Pfennigen.

Die Besteuerung des hinter einem Renteneinkommen stehenden Kapitals traf natürlich auch gerade jene Gruppen, die sich auf hohem Niveau auf ein Einkommen aus Renten zurückziehen konnten, ohne auf eine kaufmännische oder handwerkliche Tätigkeit angewiesen zu sein.

Schließlich wurden auch nicht in jeder Stadt alle Vermögensanteile gleich besteuert. So wurden 1534/1535 in Stralsund das einfache Vermögen mit $1 \%$, Weddeschatt und städtische Renten aber mit $20 \%$ von den Erträgen. Einkünfte aus Landbesitz schließlich mit 33 1/3\% veranlagt. Zwar scheint zu dieser Zeit eine Verzinsung von $5 \%$ typisch für Renten in Stralsund gewesen zu sein, es fielen aber auch noch Erträge aus Rentengeschäften des späten 15. Jahrhunderts an, als der Zinsfuß zwischen $6 \%$ und $12 \%$ lag. Dieses Kapital wurde dann mit $1,2 \%$ bis $2,4 \%$ versteuert. $^{78}$

Der Vorschoß schließlich zlelte zwar auf dẩ Einkommen jener, die über kein ausreichendes Vermögen verfügten, war aber keine Einkommensteuer, wie Ellermeyer einmal indirekt bemerkte. ${ }^{79}$ Der Vorschoß bezog sich ja eben nicht steuerlich auf das Einkommen, sondern schöpfte als Kopfsteuer jeden ungeachtet seiner wirtschaftlichen Verhältnisse gleich ab, nur dass derjenige, der über kein Vermögen verfügte, den Vorschoß aus seinem laufenden Einkommen begleichen musste. ${ }^{80}$ Wurde der Vorschoß, wie zum Beispiel in Höxter mit 5_Schillingen pro Haushalt, jährlich erhoben, ${ }^{81}$ bedeutete dies für letztere Gruppe eine beständige Abschöpfung des Einkommens. Soll nicht davon ausgegangen werden, dass diese Zahlungen zu einer schleichenden Pauperisierung führten, so musste das laufende Einkommen dieser Personen, die nur den Vorschoß zahlten, für mehr als nur die blanke Lebenserhaltung ausgereicht haben. Bei dem in Höxter um 1500 üblichen Steuersatz von einem Pfennig von jeder Mark entsprach der Vorschoß immerhin der Besteuerung von 5 Mark Vermögen in der Haupt-

\footnotetext{
${ }^{78}$ Vgl. BiederstedT. Frühneuzeitliche Steuerregister (wie Anm. 55), S. 9 f.

${ }^{79}$ Vgl. EllermeYER, Vorindustrielle Städte als Forschungsaufgabe (wie Anm. 1), S. 294.

${ }^{80}$ Auf eine Berücksichtigung des Einkommens bei der Besteuerung verweist anhand oberdeutscher Beispiele allerdings DIRLMEIER. Untersuchungen zu Einkommensverhältnissen und Lebenshaltungskosten (wie Anm. 54), S. 511-519. So wurde bei der Erhebung einer Vermögenssteuer in Zürich 1417 vorgeschrieben, ,von Leuten mit aufwendiger Kleidung oder mit gutem gewerb, aber wenig versteuerbaren Vermögenswerten, ze nemmen nach gelegenheit des gewerbes," ebd., S. 512; in eine ähnliche Richtung weisen Anordnungen in Frankfurt für das 14. und 15. Jahrhundert, nach denen Häuser entsprechend des Ertrags ihrer Vermietung zu besteuern seien, vgl. ebd., S. 514; ebenfalls in Frankfurt war 1382 Vermögensbesitzern, die kein Handwerk ausübten, vorgeschrieben, ab 50 Gulden Vermögen eine volle Rüstung zu besitzen, bei Handwerkern lag diese Grenze schon bei 30 Gulden, vgl. ebd., S. 511 .

${ }^{81}$ Vgl. RüTHING, Höxter um 1500 (wie Anm. 5), S. 29.
} 
schatzung. ${ }^{82}$ Interessant für die soziale Bewertung wird es aber, wenn der Vorschoß für einzelne Personen reduziert oder - zum Teil mit dem Zusatz ,pauper" - ganz ausgesetzt wurde. ${ }^{83}$

\subsection{Lebensläufe}

Das Verhältnis von Einkommen, Vermögen und sozialem Status folgt zudem in der Regel dem Lebenszyklus. In den ersten Jahren der Berufstätigkeit steigt das Vermögen an, bleibt, solange alle Kinder noch im Hause wohnen, zumal sobald sie zur Arbeitsleistung beitragen können, über einen längere Zeitpunkt auf dem Höhepunkt und beginnt mit der Abschichtung der ausscheidenden Kinder abzunehmen. ${ }^{84}$ Geht die Erwerbsfähigkeit verloren, kann dies auch in ein weitgehendes Aufzehren des Vermögens übergehen. ${ }^{85}$ Verlauf und Stärke der Schwankungen der Einkommens- und Vermögenshöhe hängen zudem von der Art des Erwerbs bzw. Einkommens (handwerkliche/kaufmännische Tätigkeit - Immobilien- und Rentenbesitz) und der Stellung im sozialen Beziehungsnetz ab. Für wirtschaftlich schwächere Gruppen bzw. jene, die auf die eigene Arbeitskraft zum Broterwerb angewiesen waren, konnte die Kurve deutlich schneller den Boden erreichen.

Zur Veranschaulichung dieser Wechselfälle innerhalb eines Lebensverlaufes, die sich aus 'vereirrzelter Steuerverzeichnissen kaum rekonstruieren lassen, sollen die folgenden drei Kurz-Sozialbiographien dienen: ${ }^{86}$

\section{Peter von Eventure (Greifswald)}

Der Greifswalder Krämer Peter von Eventure, der zwischen Johannis 1364 und Ostern 1366 die erste Bude in der Tuchscherreihe am Greifswalder Rathaus mietete, ${ }^{87}$ hatte bereits 1361 ein Erbe in der Kuhstraße (Abb. 3, Nr. 1) erworben. ${ }^{88} 1363$ kaufte er die westliche Ecke von Hökerstraße und

\footnotetext{
${ }^{82}$ Vgl. ebd., S. 28.

${ }^{83}$ So im Osnabrücker Vorschoß von 1447, StAOs Dep. 3b II Nr. 541.

${ }^{84}$ Zur Rolle der Familie vgl. auch Erich MASCHKE, Die Familie in der deutschen Stadt des späten Mittelalters (Abhandlungen der Heidelberger Akademie der Wissenschaften, Philosophisch-Historische Klasse. Jg. 1980. Abh. 4). Heidelberg 1980: Michael MitTerauer, Familie und Arbeitsteilung. Historisch vergleichende Studien, Wien/Köln/Weimar 1992, S. $256-300$.

${ }^{85}$ Vgl. Hammel. Hauseigentum (wie Anm. 1), S. 126.

${ }^{86}$ Für ähnliche Beispiele vgl. RÜTHING, Höxter um 1500 (wie Anm. 5), S. 178f., 197-199. 237f. und 264-268.

${ }^{87}$ Vgl. IGEL, Greifswalder und Greifswald um 1400 (wie Anm. 4), S. 278.

${ }^{88}$ Ebd., Regest KuhO02 - 30002.
} 


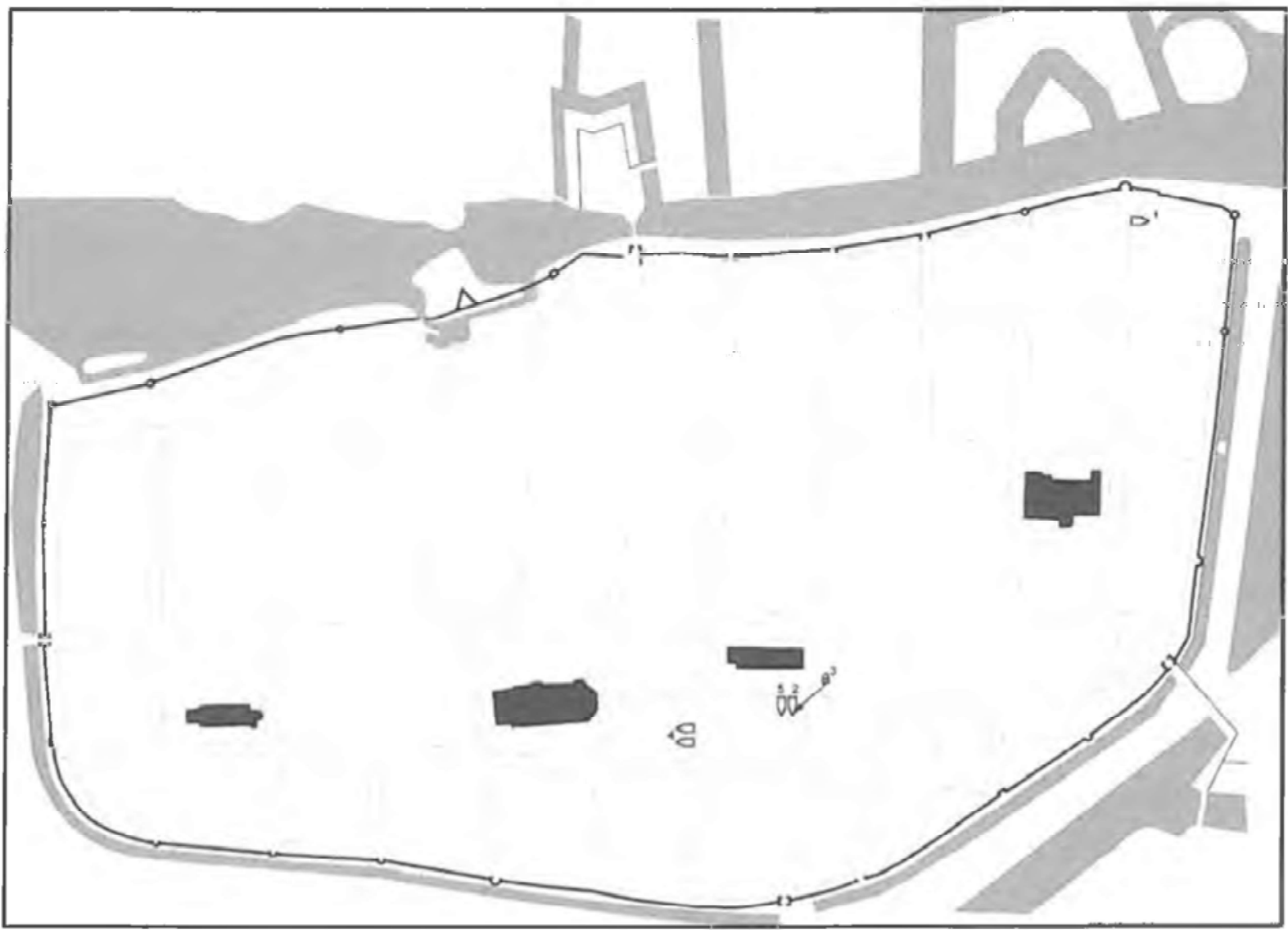

Abb. 3: Greifswald, Grundbesitz des Krämers Peter von Eventure (1361-1382)

Markt (Abb. 3, Nr. 2) ${ }^{89}$ und einen Garten vor dem Fleischertor, ${ }^{90}$ die beide zuvor dem Goldschmied Johann von Magdeburg gehört hatten. 1369 kam ein kleines Haus oder eine Bude (domuncula) neben dem bereits 1363 gekauften Eckhaus in der Hökerstraße hinzu (Abb. 3, Nr. 3). ${ }^{91}$ und 1373 zwei nebeneinander stehende Erben gegenüber dem Fleischscharren in der Kuterstraße (Abb. 3, Nr. 4). ${ }^{92}$ Im folgenden Jahr kaufte Peter von Eventure noch ein Erbe von dem Bürgermeister Everhard Rubenow neben seinem

\footnotetext{
${ }^{89}$ Ebd.. Regest MarS07 - 36101.

${ }^{90}$ Ebd., Regest 36102.

${ }^{91}$ Ebd., Regest FleW0I - 55005.

${ }^{92}$ Ebd., Regest KutW03/04 - 68104. Aus diesen beiden Erben richtete Peter von Eventure anlässlich des Kaufes eine Stiftung über $50 \mathrm{~ms}$ (Mark sundisch) für die Armen des Georghospitals ein, daraus sollten sie zu Ostern, Pfingsten und Weihnachten je eine Tonne Bier und jeden Freitag fünf Schönroggenbrote erhalten, vgl. Theodor PYL, Geschichte der Greifswalder Kirchen und Klöster sowie ihrer Denkmäler. Teile 1-3, Greifswald 1885-1887, S. 1272. Diese Stiftung wurde 1380 auf die 1369 erworbene domunculam in der Hökerstraße übertragen, die dann 1404 von Peters Sohn Jesse von Eventure an Nikolaus von Anklam verkauft wurde. Pyl vermutete noch. dass es sich dabei um die beiden 1373 gekauften Erben gegenüber des Fleischscharrens in der Kuterstraße handelte, die Pyl in der Fleischerstraße lokalisieren wollte, vgl. ebd.
} 
Eckhaus am Markt (Abb. 3, Nr. 5). ${ }^{93} \mathrm{Zu}$ diesem Zeitpunkt bestand sein Besitz aus sechs einzelnen Grundstücken und einem Garten vor dem Fleischertor, in den folgenden Jahren setzte dann nach und nach die Auflösung des Besitzes ein: bereits 1378 verkaufte er das Erbe in der Kuhstraße wieder, ${ }^{94} 1379$ tauschte er mit Johann Hagedorn seinen Garten vor dem Fleischertor, ${ }^{95} 1380$ verkaufte er beide Erben in der Kuterstraße ${ }^{96}$ und 1382 schließlich das 1363 erworbene Eckgrundstück in der Hökerstraße mit dem Garten vor dem Fleischertor an den Gürtelmacher Johann von Köln. ${ }^{97}$ Peter von Eventure behielt aber noch das Nachbargrundstück am Markt und die Bude in der Hökerstraße, die beide um 1400 noch seinem Sohn Jesse von Eventure gehörten. ${ }^{98}$ Letzterer - und dies mag auf den wirtschaftlichen Aufstieg der Familie verweisen - zählte nach eines Schiffsliste von 1388 zu jenen Greifswaldern, die sich am Getreidehandel beteiligten. ${ }^{99}$

\section{Die Familie Slupwachter (Greifswald)}

Die Greifswalder Familie Slupwachter begegnet in der Überlieferung erstmals mit dem Wollweber Albert Slupwachter, der zwischen 1377 und 1380 im Kämmereibuch mit den Abgaben für das von ihm gewebte Tuch genannt wird. Im Durchschnitt zahlte er 13,5 Schillinge im Vierteljahr, was dem unteren Mittelfeld entsprach. ${ }^{100} 1379$ erwarb Albert ein eigenes Grundstück in der Kapaunstraße, dem Greifswalder Weberviertel (Abb. 4, Nr. 1), ${ }^{101}$ bevor zwei Jahre später sein Sohn Hermann das Handwerk übernahm. Dieser zahlte 1381 nun durchschnittlich 33 Schillinge vierteljährlich, ${ }^{102}$ erwarb 1392 ein weiteres Erbe in der Kapaunstraße (Abb. 4, Nr. $2),{ }^{103}$ fünf Jahre später ein steinernes Eckhaus in der Kuterstraße mit dahinter gelegenem Getreidespeicher (Abb. 4, Nr. 3), ${ }^{104}$ verkaufte 1399 das Haus seines Vaters (Abb. 4, Nr. 1), ${ }^{105}$ um 1403 schließlich ein Erbe am

\footnotetext{
${ }^{93}$ IGEL, Greifswalder und Greifswald um 1400 (wie Anm. 4), Regest MarS06 - 72102. Everhard Rubenow behielt in diesem Erbe ein Kapital von $200 \mathrm{~ms}$, für das Peter von Eventure ihm jährlich zu Michaelis $20 \mathrm{~ms}$ Rente zahlen sollte.

${ }^{94}$ Ebd., Regest KuhO(02 - 83004.

${ }^{95}$ Ebd., Regest 88008.

${ }^{96}$ Ebd., Regest KutW03/04 - 91002.

${ }^{97}$ Ebd.. Regest MarS07 - 97102.

${ }^{98}$ Ebd., Regest MarS06 - 141105 und FleW01 - 144108.

${ }^{99}$ Vgl. ebd., S. 347-351.

${ }^{100}$ Vgl. ebd., S. 294.

${ }^{101}$ Ebd., Regest KapW08 - 87003, zum Weberviertel, vgl. ebd. S. 299.

${ }^{102}$ Vgl. ebd., S. 294.

${ }^{103}$ Ebd., Regest KapW10 - 122113.

${ }^{104}$ Ebd., Regest KutW05 - 130101.

${ }^{105}$ Ebd., Regest KapW08 - 134108.
} 


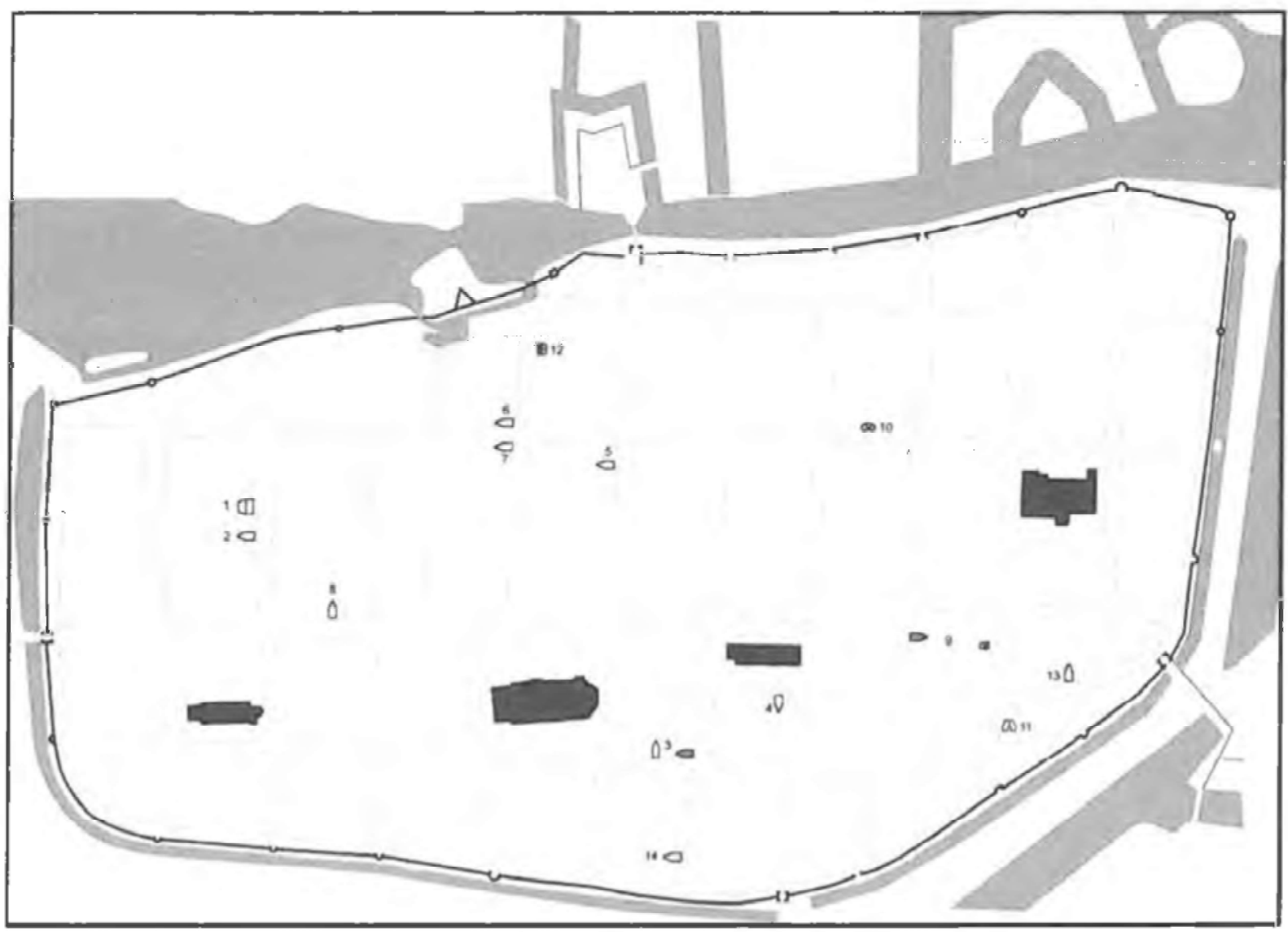

Abb. 4: Greifswald, Grundbesitz der Familie Slupwachter (1379-1451)

Markt zu kaufen (Abb. 4, Nr. 4). ${ }^{106}$ Das Eckhaus in der Kuterstraße gehörte ihm 1405 anscheinend schon nicht mehr. ${ }^{107}$ Hermann Slupwachter verfügte ab 1392 also stets über zwei bis drei Grundstücke in der Stadt, seinen Wohnsitz scheint er von der Kapaunstraße über die Kuterstraße an den Markt verlegt zu haben. Nachdem er vor 1407 verstorben war, wurde er, der 1392 noch Wollweber genannt worden war, als dominus bezeichnet. Das Haus am Markt und das Erbe in der Kapaunstraße gelangten in diesem Jahr als Mitgift an Nikolaus Schole (Abb. 4, Nr. 2 und Nr. 4), der Slupwachters Witwe geheiratet hatte. ${ }^{108}$ Hermanns Sohn Johann heiratete die Witwe des Johann Bremer, als Mitgift erhielt er 1411 ein Haus in der Steinbeckerstraße (Abb. 4, Nr. 5), das er zugleich mit 300 Mark sundisch für den Erbteil von Johann Bremers Sohn belastete. ${ }^{109}$ Sechs Jahre später kaufte er von Nikolaus Schole das väterliche Haus zurück (Abb. 4, Nr. 4), ${ }^{110}$ um anschließend 1419 das Erbe in der Steinbeckerstraße zu verkau-

\footnotetext{
${ }^{106}$ Ebd., Regest MarS06 - 141105.

${ }^{107}$ Ebd., Regest KutW05 - 148105.

${ }^{108}$ Ebd., Regesten MarS06/KapW10 - 151001.

${ }^{109}$ Ebd., Regest SteW17 - 158004.

${ }^{110}$ Ebd.. Regest MarS06 - 169117.
} 
fen (Abb. 4, Nr. 5). ${ }^{1 " \prime}$ Bevor Johann Slupwachter 1426 in den Greifswalder Rat gewählt wurde, ${ }^{112}$ erwarb er 1424 noch ein Eckhaus in der Hunnenstraße (Abb. 4. Nr. 6), ${ }^{113}$ verkaufte dann aber 1429 das Erbe in der Kapaunstraße, das schon seinem Vater und dann Nikolaus Schole gehört hatte (Abb. 4, Nr. 2), ${ }^{114}$ und im folgenden Jahr ein anderes Eckhaus, das zuvor ebenfalls im Besitz von Nikolaus Schole war (Abb. 4, Nr. 7). ${ }^{115}$ Den Verkauf eines Erbes in der Langen Straße (Abb. 4, Nr. 8), das ihm nachweislich 1430 gehörte, ${ }^{116}$ ließ er 1440 in das Stadterbebuch eintragen. ${ }^{117}$ - Da der Küufer Johann Bekermann aber schon 1436 dieses Grundstück mit einer Rente belastete, ${ }^{118}$ erfolgte der Eintrag wohl mit größerer Verspätung nach dem eigentlichen Rechtsgeschäft. Den eigentlichen wirtschaftlichen und sozialen Durchbruch hatte Johann aber wohl mit seiner zweiten Ehe vermutlich in den 1420er Jahren erreicht, als er Lutgard, die Tochter des Bürgermeisters Hinrich I. Rubenow († 1419), ehelichte. ${ }^{119}$ Zur Abfindung seiner Ansprüche auf ihren Brautschatz und den Nachlass ihres Bruders Hinrich II. Rubenow ( $†$ 1447/48), ${ }^{120}$ die sich auf 4600 Mark sundisch summierten, erhielt Johann gemäß einer nachträglich 1451 in das Stadterbebuch eingetragenen Einigung von seinem Neffen, dem Bürgermeister und späteren Universitätsgründer Hinrich III. Rubenow, noch 2500 Mark, wofür Hinrich ihm unter anderem sein Haus am Markt mit Hinterhaus in der Brüggstraße im Wert von 800 Mark (Abb. 4, Nr. 9), ein Backhaus (Abb. 4, Nr. 10) und eine Scheune (Abb. 4, Nr. 11) im Wert von je 100 Mark sowie weitere Einkünfte verschrieb. ${ }^{121}$ Auch seine dritte Ehe mit Tilseke von Dorpen erwies sich als durchaus einträglich, so überschrieb Tilsekes Bruder Johann von Dorpen ihm 1448 als Mitgift zwei Buden in der Hunnenstraße (Abb. 4, Nr. 12), ein Haus in der Fuhrstraße (Abb. 4, Nr. 13), die Hälfte eines Hauses in der Kuterstraße (Abb. 4, Nr. 14) und eine

${ }^{111}$ Ebd.. Regest SteW17 - 173008.

${ }^{1 / 2}$ Vgl. PYL, Genealogien der Greifswalder Ratsmitglieder 1382-1647 (wie Anm. 15), S. $253 \mathrm{f}$.

${ }^{113}$ IGEL, Greifswalder und Greifswald um 1400 (wie Anm. 4), Regest HunW06 - 180104.

${ }^{11+}$ Ebd., Regest KapW10 - 188101.

${ }^{115}$ Ebd., Regest HunW07 - 191001.

${ }^{116}$ Ebd.. Regest LanN20 - 189007 (östliches Nachbargrundstück).

117 Ebd., Regest LanN19 - 198012.

${ }^{118}$ StAG Rep. $3 \mathrm{Nr} .15$, f $246 \mathrm{r}$.

${ }^{119} \mathrm{Vgl}$. PYL, Genealogien der Greifswalder Ratsmitglieder 1382-1647 (wie Anm. 15), S. $198 \mathrm{f}$.

${ }^{120} \mathrm{Vgl}$. ebd. S. 268.

${ }^{121}$ IGEL, Greifswalder und Greifswald um 1400 (wie Anm. 4), Regesten MarO03/ PItNI I/FuhSO2 - 216001; vgl. PYL, Dr. Heinrich Rubenows Leben (wie Anm. 19), S. 253f. - das noch stehende Haus am Markt (heute Markt 11) war das Geburtshaus Hinrich Rubenows und wurde zumindest auch in den 1430er Jahren von diesem bewohnt, vgl. IGEL, Greifswalder und Greifswald'um 1400 (wie Anm. 4), S. 411-415. 
Scheune außerhalb des Mühlentores. ${ }^{122}$ Kurz nach Johann Slupwachters Tod verkauften die Provisoren seiner Witwe Ende 1451 oder Anfang 1452 sein väterliches Haus an der Südseite des Marktes (Abb. 4, Nr. 4). ${ }^{123}$

Die Verwandtschaft zur Familie Rubenow bestimmte auch den Weg seines Sohnes Hermann. Dieser trat dem geistlichen Stand bei, wurde 1460 von seinem Vetter Hinrich III. Rubenow an der von diesem gegründeten Greifswalder Universität promoviert, dort Professor und Dekan des Kapitels von St. Nikolai. ${ }^{124}$

\section{Ertwin Ertmann (Osnabrück)}

Der langjährige Osnabrücker Bürgermeister und Rat der Bischöfe Konrad III. und Konrad IV. von Osnabrück, zugleich Verfasser einer ersten Geschichte der Osnabrücker Bischöfe, stammte zwar nicht, wie bislang in der Forschung vertreten, aus einer Handwerkerfamilie, ${ }^{125}$ sein politischer und gesellschaftlicher Aufstieg bleibt aber dennoch bemerkenswert. So schrieb der in Osnabrück geborene westfälische Geschichtsschreiber Hermann Hamelmann schon 1564, etwas mehr als ein halbes Jahrhundert nach Ertwin Ertmanns Tod über diesen, dass er nicht aus den großen Geschlechtern Osnabrücks stammte, aber durch Tüchtigkeit und gelehrte Bildung vornehm war und so empor steigen konnte, dass niemals ein Bürgermeister größeres Ansehen in ganz Westfalen besessen habe. ${ }^{126}$ Sein Vater Johann Ertmann erscheint zwar zwischen 1437 und 1444 in den Rechnungen der Neustadt als Brauer und wurde hierin auch von seiner Witwe nachgefolgt, ${ }^{127}$ andere Belege verweisen aber darauf, dass er kaufmännisch tätig war. So wurden Waren von ihm zusammen mit denjenigen seines Bruders Ertwin Ertmann, für den ebenfalls eine Brautätigkeit nackgewiesen werden kann, ${ }^{128}$ und anderer Osnabrücker Kaufleute 1442 in Vechta und Be-

\footnotetext{
${ }^{122}$ Ebd., Regesten HunO03/FuhN02/KutW11 - 213001.

${ }^{123}$ Ebd., Regest MarS06 - 217003.

${ }^{124} \mathrm{Vgl}$. Stephanie IRRGang, Perigrinatio academica: Wanderungen und Karrieren von Gelehrten der Universitäten Rostock, Greifswald. Trier und Mainz im 15. Jahrhundert (Beiträge zur Geschichte der Universität Greifswald 4), Stuttgart 2002, S. $210 \mathrm{f}$.

${ }^{125}$ Auch Christian Hoffmann, der die Quellen zur Familie Ertmann noch einmal neu zusammengestellt hat, bezeichnet ihn als ..Brauerssohn“, Christian HofFMANN, Grenzen von Aufstieg und Etablierung in der altständischen Gesellschaft: Die Familie Ertmann in Osnabrück, in: OsnMitt. 101, 1996, S. 11-63, hier S. 12.

${ }^{126}$ Herman HamelmanN. Opera Genealogico-Historica, De Westphalia \& Saxonia inferiori, congesta ab Ernesto Casimiro Wasserbach. Lemgo 1711, S. 645.

${ }^{127}$ Vgl. HoffmanN, Grenzen von Aufstieg und Etablierung (wie Anm. 125), S. 16; Johann Ertmann starb vor 1447, da in dem Vorschoßregister aus diesem Jahr seine Witwe als in der Johannisstraße wohnend erscheint, StAOs Dep. 3b II Nr. 541.

${ }^{128}$ Vgl. HoffmanN, Grenzen von Aufstieg und Etablierung (wie Anm. 125), S. 16.
} 
vergern von den Amtsleuten des Bistums Münster beschlagnahmt. ${ }^{129} \mathrm{Er}$ war eben nicht Brauer, sondern wohl eher Kaufmann, der auch als Brauer tätig war, ein Gewerbe, das in Osnabrück frei, weder an bestimmte Häuser, noch an ein Amt gebunden war. ${ }^{130}$ Unter den über 120 in den Akziserechnungen von 1449 genannten Brauern fanden sich verschiedene Gewerbe, vor allem auch Bäcker, Mitglieder unterschiedlicher Sozialgruppen bis hin zu führenden Ratsherren. ${ }^{131}$ Die wirtschaftlichen Verhältnisse der Familie waren jedenfalls so gut, dass dem Sohn 1443 die Immatrikulation an der Universität Erfurt möglich war, an der er 1445 den Baccalaureus Artium erwarb. Auf den Zeitpunkt seiner Rückkehr und die ersten Jahre in Osnabrück fehlen Hinweise in den Quellen. Etwas über 20 Jahre alt, wurde Ertwin Ertmann dann 1451 in den Rat der Osnabrücker Neustadt gewählt, im gleichen Jahr beerbte er seinen Onkel gleichen Namens und erhielt so neben dessen Wohnhaus in der Hasestraße verschiedene Ländereien vor der Stadt, Geldrenten in Höhe von rund 16 Goldgulden und eine Pfandschaft über 12 Goldgulden. Seinen eigentlichen wirtschaftlichen und politischen Aufstieg verdankte er aber wohl der Nähe zu dem Osnabrücker Bischof Konrad III. von Diepholz, in dessen Diensten er spätestens seit 1457 stand. ${ }^{132}$ Zwischen 1460 und 1470 erhielt Ertmann von diesem über 20 Höfe und Kotten zu Lehen und 1465 die Poggenburg westlich der Katharinenkirche in der Osnabrücker Altstadt, die zuvor im Besitz des Bürgermeisters Hermann von Melle gewesen war. ${ }^{133}$ Der Umzug in das Viertel um St. Katharinen - bis dahin wird er vermutlich das elterliche Haus in der Johannisstraße bewohnt haben - bedeutete zugleich auch einen Wechsel in den Altstädter Rat. Der direkte Übergang vom Rat der einen in den der anderen Teilstadt verweist auch auf seine inzwischen etablierte Stellung, denn immerhin musste hierfür einer der vier bisherigen Ratsherren der Butenburg ausscheiden bzw. auf seine möglich Wiederwahl verzichten, es sei denn, einer war gerade verstorben. ${ }^{134}$ Sein neuer

${ }^{129}$ StAOS Dep. 3a 1 IV Nr. 193/2.

${ }^{130} \mathrm{Vgl}$. Carl Bertram STüve. Gewerbswesen und Zünfte in Osnabrück, in: OsnMitt. 7, 1864, S. 23-227, hier S. 30f.

${ }^{131}$ StAOs Dep. 3b II Nr. 492; vgl. dazu Karsten IGEL, Möglichkeiten einer Sozialtopographie des spätmittelalterlichen Osnabrücks, in: OsnMitt. 109, 2004 (im Druck).

${ }^{132} \mathrm{Vgl}$. Hoffmann, Grenzen von Aufstieg und Etablierung (wie Anm. 125), S. 17.

${ }^{133}$ StAG Dep. 3b II Nr. 539; ein Ratsherr Johann Poggenburg erscheint bereits 1283, Osnabrücker Urkundenbuch Bd. 4, Nr. 107 - 1283 Oktober 5.

${ }^{134}$ Zur Ratsverfassung und -wahl in Osnabrück vgl. Klaus WRIEDT, Ratsverfassung und städtische Gesellschaft im spätmittelalterlichen Osnabrück, in: OsnMitt. 94, 1989, 11-26; Dietrich W. POECK, Rituale der Ratswahl in westfälischen Städten, in: Vormoderne politische Verfahren, hg. von Barbara STOLLBERG-RILINGER (Zeitschrift für Historische Forschung, Beiheft 25), Berlin 2001, S. 207-262, hier S. 207-218; DERS., Rituale der Ratswahl. Zeichen und Zeremoniell der Ratssetzung in Europa (12.-18. Jahrhundert) (Städteforschung A/60), Köln/Weimar/Wien 2004, S. 67-74. 
Wohnsitz lag nun mitten in dem Bereich, in dem die Osnabrücker Geschlechter wohnten. So wohnte sein zukünftiger Schwager, der Bürgermeister Gottschalk von Ankum, fast in unmittelbarer Nachbarschaft zu ihm. ${ }^{135}$ Um 1470 heiratete er dessen Schwester Christine, neben dem Nutzen der nicht genauer überlieferten Mitgift war er so auch im Konnubium mit den führenden Geschlechtern der Stadt verbunden. Nachdem Christine von Ankum bereits 1481 oder 1482 verstorben war, ehelichte Ertmann im März 1483 Anna, Tochter des Ratsherrn Otto Spieker und Witwe des Bürgers Burkhard Sleter, dessen Nachlass, unter anderem zwei Häuser in Osnabrück und seine Osnabrücker und Herforder Lehngüter, sie mit in die Ehe brachte. $\mathrm{Zu}$ diesen Gütern zählte auch der Besitz Uphausen (heute Haus Brandenburg) bei Bissendorf, ${ }^{136}$ dessen um 1500 errichtetes Herrenhaus in Gestalt und Proportionen dem Osnabrücker Rathaus, das seit 1487 maßgeblich unter Ertmanns Ägide entstand, ausgesprochen ähnelt und so als bauliches Relikt auf seinen sozialen Anspruch verweisen könnte. ${ }^{137}$ Die in Stadt und Stift erlangte Position spiegelte sich schließlich 1488 in der Verheiratung Ertwin Ertmanns ältester Tochter Christine mit Lüdeke von Bar aus der führenden Adelsfamilie des Stiftes, der später als Erblanddrost an der Spitze der Osnabrücker Ritterschaft stand. Ihre Mitgift umfasste einen Hof in Osnabrück und 500 Goldgulden. Seine fünf Söhne nahmen allesamt ein Universitätsstudium auf, drei erhielten ein Kanonikat am Jo-

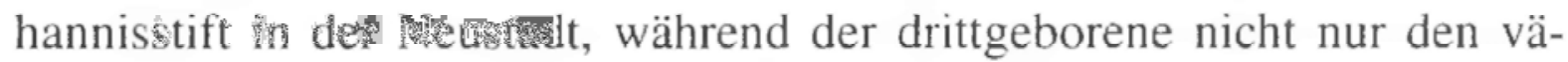
terlichen Namen führte, sondern ihm auch in seinen Ämtern als Ratsherr und Bürgermeister, aber auch als Lehensrichter des Bischofs nachfolgte. In seinen Besitz gelangte ebenso die Poggenburg. ${ }^{138}$ Allein der jüngste Sohn Johann, der sich 1502 an der Universität Erfurt einschrieb und über ein reiches Erbe verfügte, verweist mit seiner Biographie darauf, wie schnell der soziale Abstieg erfolgen konnte. Nachdem er schon 1518 und $1522 \mathrm{im}$ Zusammenhang mit Gewalttaten in Erscheinung trat und $\mathbf{1 5 2 3}$ Lehngüter aus dem ehemals mütterlichen Besitz, darunter auch das Gut zu Uphausen, an die Gräfin von Tecklenburg veräußern musste. war er 1525

\footnotetext{
${ }^{135}$ Die Wohnlage Gottschalck von Ankums ergibt sich aus den Steuerverzeichnissen von 1447 und 1463, StAOs Dep. 3b II Nr. 539 und Nr. 541.

${ }^{136} \mathrm{Vgl}$. Rudolf VOM BRUCH, Die Rittersitze des Fürstentums Osnabrück, Osnabrück 1930, S. 107 f.; Edgar F. WARNECKE, Das große Buch der Burgen und Schlösser im Land von Hase und Ems, Osnabrück 1980. S. 83-85.

${ }^{137} \mathrm{Im}$ ab 1487 neuerbauten Rathaus ließ Ertwin Ertmann wie die Bürgermeister und Ratsherren Hinrich von Leden. Hinrich Vrese, Gottschalk von Ankum und Gerd von Dumpstorp sein Wappen in Kapitelle schneiden. Zudem war er als Kirchenrat am Bau des gewaltigen Turmes von St. Katharinen beteiligt, vgl. dazu unten den Abschnitt „Soziale Struktur und städtische Sakrallandschaft".

${ }^{138} \mathrm{Vgl}$. HofFMANN, Grenzen von Aufstieg und Etablierung (wie Anm. 125), S. 33-35.
} 
unter den Aufrührern des Oberg-Aufstandes, ${ }^{139}$ was ihm Haft im Bucksturm und 500 Goldgulden Strafe einbrachte. ${ }^{1 / 0}$

Sicherlich sind diese Beispîle nicht repräsentativ und die Wege und Möglichkeiten eines sozialen Aufstiegs in der spätmittelalterlichen Stadtgesellschaft wären noch gründlich zu untersuchen, aber sie verweisen deutlich auf die möglichen Veränderungen, die sich während einer - oder auch über mehrere Generationen hinweg ergeben konnten. Für den Krämer Peter von Eventure zeigte sich ein fast idealer Kurvenverlauf im Blick auf seinen Immobilienbesitz. Innerhalb von 13 Jahren erwarb er bis 1374 immerhin sechs Grundstücke in Greifswald - ein Besitz, der weit umfangreicher als der vieler Ratsherren oder Gewandschneider war. ${ }^{141}$ Acht Jahre später besaß er aber wiederum nur noch zwei Grundstücke. Auch wenn der Immobilienbesitz seine Vermögensverhältnisse nur mit einer gewissen Unschärfe widerspiegeln sollte, so kann hier doch von deutlichen Veränderungen über sein Erwerbsleben hinweg ausgegangen werden.

Im Falle der vier vorgestellten Generationen der Familie Slupwachter ist hier vor allem Hermann Slupwachter von Interesse. Während sein Vater anscheinend erst sehr spät Grundeigentum erwerben"konnte, schüf er die eigentliche Grundlage für den sozialen Aufstieg der Familie, von dem er aber selbst schon deutlich profitierte, was sich nicht nur im Umfang des Eigentums, sondern auch in der Anrede als dominus zeigt. Sein Erwerbsleben begann er wie sein Vater als Wollweber, hinter der weiteren Entwicklung dürfen aber wohl mehr kaufmännische Aktivitäten vermutet werden, wofür auch der Kauf eines Hause mit Getreidespeicher spricht. Seine ursprüngliche Tätigkeit als Wollweber deutet zudem auf den Wandschnitt. Wie Peter von Eventure seinen Wohnsitz aus der Kuhstraße an den Markt verlagerte, zog auch Hermann Slupwachter parallel zu seinem wirtschaftlich-sozialen Aufstieg aus dem Wollweberviertel in der Kapaunstraße über die Kuterstraße in der Nähe des Marktes schließlich an die Südseite des Marktes, unmittelbar dem Rathaus gegenüber. Für seinen Sohn Johann war so die Grundlage gelegt, sich über die Eheverbindung mit der Familie Rubenow endgültig in der Greifswalder Führungsschicht zu etablieren. Eine familiäre Verbindung, die auch für die folgende Generation von wesentlicher Bedeutung war.

\footnotetext{
${ }^{130}$ Vgl. Wilfried EHBRECHT. Der Oberg-Aufruhr von 1525. Zu antikirchlichen Tendenzen in den Stadtkonflikten Osnabrücks zwischen Mittelalter und Neuzeit, in: Konsens und Konflikt. Skizzen und Überlegungen zur älteren Verfassungsgeschichte deutscher Städte von Wilfried Ehbrecht, hg. von Peter JOHANEK (Städteforschung A/56), Köln/Weimar/Wien 2001, S. 332-342.

${ }^{140} \mathrm{Vgl}$. HoffmanN, Grenzen von Aufstieg und Etablierung (wie Anm. 125), S. $36 \mathrm{f}$.

${ }^{141}$ Vgl. IGEL, Greifswalder und Greifswald um 1400 (wie Anm. 4), S. 248 Abb. 34 und S. 331 Abb. 50.
} 
Dass Ertwin Ertmann in Osnabrück überhaupt so einen bemerkenswerten Aufstieg nehmen konnte, verdankte er dem Vermögen seiner Eltern, dessen Umfang zumindest ein Universitätsstudium des Sohnes erlaubte, zudem konnte er nach seiner Rückkehr seinen kinderlosen Onkel beerben. Der eigentliche Aufstieg war aber Ergebnis seines Studiums, seiner Fähigkeiten und der so erlangten Position als Vertrauter und Rat des Bischofs, dem er einen großen Teil seines Vermögens und den Aufstieg in die Lehnsmannschaft des Stiftes verdankte. Zwischen dem jungen Ratsherrn der Neustadt und dem langjährigen Bürgermeister der Altstadt, der zudem Schwiegervater des Erblanddrosten Lüdeke von Bar war, lagen Welten. Auch im Falle Ertmanns wurde der entscheidende Moment seines Aufstiegs von einem Umzug innerhalb der Stadt oder besser zwischen den beiden Osnabrücker Teilstädten markiert. Von der Johannisstraße aus bezog er die Poggenburg in dem innerhalb der Stadt herausragenden Quartier um die Katharinenkirche inmitten der führenden Geschlechter Osnabrücks. Hinzu kam mit dem Gut Uphausen aber auch noch ein befestigter Sitz außerhalb der Stadt.

Neben den wirtschaftlich-sozialen Veränderungen über den Lebenszyklus hinweg fällt für alle drei Beispiele die Veränderung des Wohnsitzes innerhalb der Stadt im Zusammenhang mit dem sozialen Aufstieg auf. Dies verweist einmal mehr darauf, dass es eben nicht unerheblich war, wo man in der Stadt lebte und umgekehrt auch der Wohnort bis zu einem bestimmten Grade auf die Position innerhalb der städtischen Gesellschaft verweisen kann. Für Osnabrück zeigt sich zudem, dass dies auch Orte weit ab vom Markt, dem wirtschaftlichen und politisehen Zentrum, sein konnten. ${ }^{142}$

\subsection{Schicht oder Gruppe?}

Vermögen lassen sich je nach Quellenlage und Form der Besteuerung mehr oder minder genau für einen oder auch mehrere Zeitpunkte bestimmen. Dies allein genügt aber nicht für die soziale Positionierung einer Einzelperson. Notwendig wäre zuerst einmal, wie aus den angeführten Lebensläufen ersichtlich, die Entwicklung des Vermögens über einen längeren Zeitraum zu verfolgen, was häufig an der Quellenlage scheitern dürfte und zudem einen hohen Arbeitsaufwand für die Untersuchung cincr größeren Personengruppe erfordert. ${ }^{143}$ Dies ist aber eigentlich die conditio

\footnotetext{
${ }^{142}$ Vgl. IGEL, Von der Straße zum Platz (wie Anm. 35), S. 187-192; Ders., Auf der Spur des Stadt-Raums (wie Anm. 43), S. 157 f.

${ }^{143}$ Beispielhaft RüTHING, Höxter um 1500 (wie Anm. 5).
} 
sine qua non für die Untersuchung der Sozialstruktur einer Stadtgesellschaft auf der Basis von Steuerverzeichnissen, wenn dabei Einzelpersonen nach ihrem Vermögen in ein irgendwie geartetes Ordnungsschema eingefügt werden sollen. Wichtig ist aber auch die Betrachtung der sozialen Beziehungen, der Zugehörigkeit zu einer Sozialgruppe und den Möglichkeiten, die sich daraus für den Einzelnen wie für Personengemeinschaften ergaben. Die Sozialgruppe hat dabei nichts mit irgendeinem Schichtungsmodell zu tun, sondern ist in sich sozial wie wirtschaftlich differenziert, bildet aber als Rat, als Handwerksamt oder kaufmännische Korporationen geschlossene Gruppen, die allerdings auch Verbindungen und Schnittmengen $2 u$ anderen Sozialgruppen aufwiesen. ${ }^{144}$

Die zum Teil ausgesprochen breite Streuung der Vermögen innerhalb der verschiedenen handwerklichen und kaufmännischen Gruppen kann Heinrich Rüthing auf der Basis eines Schoßregisters von 1482 bis 1517 für Höxter sehr anschaulich vor Augen führen. Gleiches gilt für die Vermögensentwicklung einzelner Mitglieder dieser Sozialgruppen. ${ }^{145}$ Die Gütliche Kontribution von 1487 bietet für Osnabrück dagegen zwar nur einen zeitlichen Ausschnitt, verweist innerhalb dieses Rahmens aber auf vergleichbare Streuungen. Der durchschnittliche Schoß lag für alle 1529 aufgeführten Steuerzahler bei 145,9 Pfennigen. Für die 22 Gildemeister, als Vertreter der Elf-Ämter Mitglieder des Großen Rates, lag er mit 441,8 Pfennigen fast bei dem dreifachen dieses Durchschnitts, zugleich aber auch deutlich hinter den 25 Vertretern des sitzenden und des alten Rates, die im Durchschnitt 1931 Pfennige zahlten. ${ }^{146}$ Während der ,ärmste“ unter diesen aber immer noch 576 Pfennige zur Steuer beitrug, war die Spannbreite innerhalb der 22 Gildemeister weit größer. An ihrer Spitze stand mit 1440 Pfennigen Sweder Nolleke, der, da er die Stadt mit Blei und einer Eisenkette belieferte, ${ }^{147}$ wohl einer der Gildemeister des Schmiedeamtes war. Mit großem Abstand und 864 Pfennigen folgten Helmich Knokenhouwer, anscheinend Knochenhauer sowie der Bäcker Roleff Honeborch $^{148}$ und der Krämer Bernd von Selxen ${ }^{149}$ mit je 720 Pfennigen. Drei der Gildemeister, Ludeke von Horsten, Gerd Redeker und Lambert Wolteking, zahlten mit 72 Pfennigen aber gerade einmal die Hälfte von dem Durchschnitt aller Steuerzahler und nur ein Zwanzigstel des Betrages von Sweder Nolleke. Dass sich solche Unterschiede auch innerhalb der Ämter

\footnotetext{
${ }^{144}$ Vgl. IGEL, Greifswalder und Greifswald um 1400 (wie Anm. 4), S. 235-241.

${ }^{14.5} \mathrm{Vgl}$. RÜTHING, Höxter um 1500 (wie Anm. 5), S. 151-239.

${ }^{146} \mathrm{Vgl}$. RotherT, Geschichte (wie Anm. 34), S. 345 f.

${ }^{147}$ Vgl. EBERHARDT, Städtischer Alltag (wie Anm. 36), S. 362 und S. 491.

${ }^{148}$ Vgl. Das älteste Stadtbuch von Osnabrück (wie Anm. 39), S. 121 f.

${ }^{149}$ StAOs Dep. 3a 1 XII Nr. $40^{7}-1494$ April 26.
} 
fanden zeigt ein Blick auf die 39 Bäcker, die sich im Verzeichnis der Gütlichen Kontribution identifizieren lassen. ${ }^{150}$ Die beiden Gildemeister Roleff Honeborch und Detmar Leffardinck leisteten mit 720 Pfennigen bzw. 576 Pfennigen Beträge, die sie unter den 22 Gildemeistern im oberen Bereich einordneten, gleiches gilt auch für Bernd Yossinckhus, der ebenfalls 720 Pfennige zahlte. Auch der Durchschnitt für diese 39 Bäcker lag mit 179,4 Pfennigen über dem Wert für alle Steuerzahler, doch erreichten 19 von ihnen nur die Hälfte von diesem oder weniger. Drei der Bäcker zahlten sogar nur 12 Pfennige und damit den Mindestbetrag, der dem üblichen Vorschoßsatz in Osnabrück entsprach - einer dieser drei wurde ausdrücklich als pauper bezeichnet.

Die Gruppe der Gesellen, Lehrlinge, Mägde und Knechte als wesentlicher Kern der städtischen Unterschicht fehlt, wie bereits angemerkt, ohnehin fast völlig in den Quellen. ${ }^{151}$

\subsection{Die Frage der Parzelle}

An die Frage nach Vermögen und sozialer Position schließt sich die Suche nach der räumlichen Position in der Stadt an. Als Ideal steht hier natürlich die Parzellengenauigkeit, das heißt der Versuch, eine Person einer bestimmten, möglichst genau zu begrenzenden Parzelle zuweisen zu können. Dies erlaubt dann auch, archäologische und bauhistorische Befunde bestimmten Personen und Familien zuzuordnen. ${ }^{152}$ Allein aus den Angaben in Steuerverzeichnissen ist dies aber kaum zu leisten. ${ }^{153}$ Erstes und durchaus lösbares Problem bildet dabei der Steuerumgang innerhalb der Stadt und der Straßen. Innerhalb der Straßen gab es hier im Grundprinzip drei Möglichkeiten: Beide Straßenseiten konnten in gleicher Richtung abgeschritten und nacheinander eingetragen werden, ebenso konnten die Steuereinnehmer auf der einen Seite hin und auf der anderen Seite zurück gehen oder sie nahmen beide Straßenseiten, einem Zickzackkurs folgend, gleichzeitig auf. Problematisch wird es vor allem, wenn nicht ein System durchgehalten wurde. So ergab ein Vergleich zweier Osnabrücker Steuerverzeichnisse aus den Jahren 1447 und 1463, dass für das Vorschoßre-

\footnotetext{
${ }^{150}$ Die 43 von BoHmBACH, Gütliche Kontribution (wie Anm. 42), S. 48 erwähnten Bäcker ließen sich trotz genauer Überprüfung nicht nachweisen. Ein Verzeichnis der Bäcker findet sich im Statut des Backamtes von 1483, vgl. Das älteste Stadtbuch von Osnabriuck (wie Anm. 39), S. $121 \mathrm{f}$.

${ }^{151} \mathrm{Vgl}$. IGEL, Auf der Spur des Stadt-Raums (wie Anm. 43), S. 142 Tab. 1.

${ }^{152} \mathrm{Vgl}$. zum Beispiel ANSORGE/IGEL/SCHÄFER/WIETHOLD, Ein Holzschacht aus der Baderstraße 1 in Greifswald (wie Anm. 25); SAMARITER/IGEL/SCHÄFER, Ein cuir-bouilli-Becher und die Patrizierfamilie Lowe (wie Anm. 25).

${ }^{153}$ Vgl. auch SCHOCH, Die Bevölkerung der Stadt St. Gallën (wie Änm. 5), S. 19-30.
} 
gister von 1447 alle drei Verfahren innerhalb eines Stadtviertels nachgewiesen werden können! ${ }^{154}$

Schwerwiegender ist die Frage, ob von der Steuer befreite Einwohner und Bürger in den Verzeichnissen aufgeführt werden oder nicht, was aus den Quellen selbst natürlich nur begrenzt zu erschließen ist. ${ }^{155}$ Ist letzteres der Fall, ergeben sich innerhalb der Straßen nur schwer nachvollziehbare Lücken in der Bewohnerabfolge, die ebenfalls nicht aus den Registern abgelesen werden können, und leerstehende Häuser wurden natürlich in den Schoßregistern übergangen. Eine Rekonstruktion ist zwar unter zur Hilfenahme von Renten- und Kaufbriefen möglich, diese nennen die Eigentümer der Häuser, aber nicht notwendig deren Bewohner, was im nicht seltenen Fall von vermieteten Häusern das Problem bestehen lässt. ${ }^{156}$ Leichter erkennbar, aber auch nicht erfreulicher ist es, wenn, wie im Jahr 1487 der 64 Personen umfassende Große Rat in Osnabrück, bestimmte Gruppen gesondert und nicht nach ihrem Wohnort aufgeführt wurden. ${ }^{157}$

Hinzu kommen Mieter, die auf dem gleichen Grundstück wie ihre Vermieter lebten, aber als eigenständiger Haushalt Steuern zahlten. Sie konnten mit im Haus, in rückwärtigen oder straßenseitig anschließenden Bauten wohnen. In den Rostocker Schoßverzeichnissen lassen sich diese Personen gut identifizieren, da die Schreiber hinzufügten, bei wem sie wohnten. ${ }^{158}$ Ähnliches gilt für das Steuerverzeichnis der Altstadt Osnabrück von $1463 .{ }^{159}$ Die räumliche Anordnung innerhalb des Grundstückes lässt sich hieraus allerdings nicht erfassen.

Das größte Hindernis liegt also in der Bestimmung von Lage und Größe der Parzelle. Möglich ist diese, wenn die Ausmaße der mittelalterlichen Bebauung aus noch existierenden Kellern und/oder Brandmauern oder dank großflächiger Ausgrabungen nachvollzogen werden können. Eine sichere Zuweisung ist aber auch dann nur durchführbar, wenn dies für ganze Straßenzüge oder zumindest längere Abschnitte gilt. Vergleichsweise gut sind die Bedingungen hierfür in den Städten lübischen Rechtes mit den ab dem ausgehenden 13. Jahrhundert vorgeschriebenen Kommun-

\footnotetext{
${ }^{154}$ Vgl. IGEL, Möglichkeiten (wie Anm. 131).

${ }^{155}$ Interessanterweise erscheinen in den sehr detaillierten Steuerverzeichnissen der Osnabrücker Altstadt aus dem Jahr 1463 die steuerbefreiten Bewohnerinnen einiger Beginenhäuser um die Katharinenkirche, aber nicht die in den gleichen Straßen wohnende Geistlichkeit dieser Kirche, StAOs Dep. 3b II Nr. 539.

${ }^{156} \mathrm{Zu}$ den Mietern vgl. IGEL, Greifswalder und Greifswald um 1400 (wie Anm. 4), S. 376-386; DERS. Auf der Spur des Stadt-Raums (wie Anm. 43). S. 153-156.

${ }^{157} \mathrm{Vgl}$. ROTHERT, Geschichte (wie Anm. 34), S. 345 f.

${ }^{158}$ Freundliche Mitteilung Frau Julia Hamelmann, Münster.

${ }^{159} \mathrm{Vgl}$. IGEL, Auf der Spur des Stadt-Raums (wie Anm. 43), S. 141-146.
} 
brandmauern, ${ }^{160}$ die in weiten Teilen dieser Städte zu einer dauerhaften Verfestigung der Parzellengrenzen bis in die Gegenwart führten. ${ }^{161}$ Aber auch dort wurde mit Budenreihen, die zwischen den einzelnen Wohnungen keine Brandmauern besaßen, dieses Baugebot unterlaufen und schließlich kam es durch spätere Schrumpfungsprozesse, Brände und Kriegszerstörungen zu tiefgreifenden Veränderungen, die die ursprünglichen Strukturen verschüttet haben. In Greifswald führte die Gründung von Kollegiatstift und Universität $1456 \mathrm{zu}$ einer Umformung eines Teiles der Stadt, in der Neustadt hatte sich das ursprüngliche Grundstückraster in der Folge eines Brandes um die Mitte des 15. Jahrhunderts und wohl eines Bevölkerungsrückganges aufzulösen begonnen. Es folgten Kriegszerstörungen des 17. Jahrhunderts, die auch zentrale Bereiche der Stadt am Hafen be ̈rafeñ. Bei der Aufnahme des ältesten Katasters, der schwedischen Matrikel von $1707,{ }^{162}$ lagen große, im Mittelalter bebaute Flächen wüst. Im Zusammenhang von Niedergang des Greifswalder Seehandels und der Entstehung der Universität kann in der Folge eine regelrechte Abwendung vom Hafen beobachtet werden, der so vom Eingangstor zur Hintertür wurde - die Folgen zeigen sich noch heute in der städtischen Struktur. ${ }^{163}$

Eine wirkliche Parzellengenauigkeit lässt sich für eine Stadt von gewisser Größe also kaum erreichen und das Ergebnis würde in der Regel auch nicht den notwendigen Arbeitsaufwand rechtfertigen. Dies wäre nur für Bereiche der Fall, in denen sich eine Verknüpfung mit archäologischen und bauhistorischen Befunden anbietet. Sonst genügt eine relative Topographre, wie zum Beispiel von Heinrich Rüthing für Höxter verwandt, ${ }^{164}$ vollauf, so dass sich die einzelnen Haushalte in der aus den Steuerregistern erkennbaren Reihenfolge mehr oder minder genau in einem Straßenabschnitt lokalisieren lassen. Denn für eine sozialtopographische Untersuchung ist schließlich nicht entscheidend, wie sich einzelne Grundstücke

\footnotetext{
${ }^{160} \mathrm{Vgl}$. dazu jetzt Jens Christian HOLST, Lübisches Baurecht im Mittelalter, in: Jahrbuch für Hausforschung 49: Historischer Hausbau zwischen Elbe und Oder, Marburg 2002, S. $115-182$.

${ }^{161}$ Vgl. Rolf Hammel-KIESOW, Quellen und Methoden zur Rekonstruktion des Grundstücksgefüges und der Baustruktur im mittelalterlichen und frühneuzeitlichen Lübeck, in: Wege zur Erforschung städtischer Häuser und Höfe (Häuser und Höfe in Lübeck 1), hg. von Rolf Hammel-Kiesow, Neumünster 1993, S. 39-152; Stefanie BrüggemanN. Der Stralsunder Kellerplan. Erste Ergebnisse einer systematischen Erfassung. in: Jahrbuch für Hausforschung 49: Historischer Hausbau zwischen Elbe und Oder, Marburg 2002, S. 261-285.

${ }^{162}$ Die Schwedische Landesaufnahme von Vorpommern 1692-1709 (wie Anm. 26).

: 63 Vgl. dazu Barbara RIMPEL, Stadtgestalt und Stadtbild Greifswalds vom Mittelalter bis 1780, in: Greifswald. Geschichte der Stadt (wie Anm. 9), S. 451-467; Klaus HaEsE, Stadtentwicklung Greifswalds im 19. Jahrhundert, in: ebd. S 469-474.

${ }^{16+}$ Vgl. RüTHING, Höxter um 1500 (wie Anm. 5), S. 16-19.
} 
unterschieden, sondern einzelne Straßen und Bereiche der Stadt - also in welcher Relationen verschiedene städtische Teilräume zueinander standen. Für Lübeck kann Rolf Hammel-Kiesow eine solche sozialräumliche Gliederung auch auf der Ebene einzelner Baublöcke nachweisen, die in ihrer sozialen Ordnung so die Stadt im Kleinen widerspiegelten. Die Struktur des Blockes stand dabei natürlich im Zusammenhang mit seiner Lage im sozialräumlichen und wirtschaftstopographischen Gefüge der Stadt. ${ }^{165}$ Angesichts der in Lübeck zu beobachtenden großen zeitlichen Konstanz dieser Strukturen ist allerdings auch zu fragen, inwieweit hier die Bauvorschriften des lübischen Rechtes eine zementierende Funktion hatten, was für eine Übertragbarkeit des Konzeptes auf Städte, die keine Kommunbrandmauern kannten, von wesentlicher Bedeutung ist. Mit dieser Frage bietet sich aber ein interessanter Ansatz, die Auswirkungen von Veränderungen in der städtischen Sozialstruktur auf die bauliche Struktur von Städten unterschiedlichen Regionen zu vergleichen.

\section{Die Stadt als sozialer Raum}

Die bisherigen Betrachtungen haben sich kritisch mit dem methodischen Vorgehen vieler - nicht aller - älteren Arbeiten auseinandergesetzt. Die Kritik konzentriert sich einerseits auf die Methoden der sozialen Stratifikation und andererseits auf den häufig nur dünnen Zeitschnitt der Betrachtung, der eher das Standbild einer Gesellschaft zeigt und so die wesentlichen Fragen nach den Strömungen und Veränderungen ausblendet. Heinrich Rüthings „Höxter um 1500“ bildet hier eine exemplarische Ausnahme. ${ }^{166}$ Gleiches gilt für das große Eubecker Projekt, das aufgrund der Größe von Stadt und gestecktem Rahmen bislang aber nur Teilergebnisse für einzelne Bereiche und Gruppen präsentieren konnte. ${ }^{167}$ Beiden Untersuchungen ist gemein, dass sie mehr als nur die quantifizierbaren Quellen wie Steuerlisten zur Grundlage nehmen, sondern die Stadt insgesamt, ihre bauliche Gestalt, die sakrale und wirtschaftliche Topographie miteinbeziehen und so versuchen, ein Gesamtbild von Stadt und städtischer Gesellschaft zu zeichnen. Es soll daher in den nun folgenden Ausführungen darum gehen, wie sich die verschiedenen schriftlichen Zeugnisse, deren Möglichkeiten und Probleme bereits diskutiert wurden, mit archäologischen und bauhistorischen Befunden zu einem Gesamtbild des

\footnotetext{
${ }^{165}$ Vgl. HAMMEL-KıESOW, Entstehung des sozialräumlichen Gefüges (wie Anm. 5), Abschnitt 5: Die Stadt im Kleinen; DERS., Quellen und Methoden (wie Anm. 161), S. 123-125. ${ }^{166}$ RÜTHING, Höxter um 1500 (wie Anm. 5).

${ }^{167} \mathrm{Vgl}$. Hammel, Hauseigentum (wie Anm. 1); Wege zur Erforschung städtischer Häuser und Höfe (Häuser und Höfe in Lübeck 1), hg. von Rolf HAMMEL-KIESOW, Neumünster 1993.
} 
sozialen Stadt-Raums verknüpfen und welche Aussagen sich so gewinnen lassen. ${ }^{168}$ An die Stelle einer Sozialtopographie sollte auf diesem Wege eine Soziologie des städtischen Raumes treten. Zuerst ist daher darzulegen, was unter der sozialen Komponente des Raumes zu verstehen ist.

\subsection{Stadt-Raum und Sozialgeschichte}

Der Raum als historische Kategorie ist - bedingt durch die nationalsozialistische Lebensraumideologie und die damit in Teilen verbundene „Raumforschung“ - in der Historiographie der vergangen Jahrzehnte nur wenig beachtet worden. ${ }^{169}$ Nach der sozialgeschichtlichen Wende, der Hinwendung zur historischen Anthropologie, zur Erforschung von Ritual und symbolischer Kommunikation u.ä. ist ein spatial turn mehr als überfällig, denn all dies findet im Raum statt, wird durch dessen Gestalt geprägt und gestaltet ihn zugleich mit. Wič dic Zeit verknüpft der Raum einzelne Ereignisse miteinander, sorgt dafür das Ungleichzeitiges gleichzeitig wird wie es in der Gestalt der mittelalterlichen und modernen Stadt unschwer erkennbar ist.

Raum in diesem Sinn ist kein Kontinuum, sondern ein Netzwerk miteinander verknüpfter Räume unterschiedlicher Gestalt, Funktion und sozialem Gepräge. So ist auch der Stadt-Raum (der Bindestrich zur Unterscheidung vom städtebaulichen „Stadtraum“) aus funktional und sozial verschiedenen Räumen zusammengesetzt, bildet (für die vormoderne Stadt) aber innerhalb der Mauern zugleich einen Gesamtraum, der sich in Teilen auch über diese hinaus erstreckt. Anders als für das Land jenseits der Mauern ist die mittelalterliche Gestalt der Stadt noch in Relikten aus Bauten und Straßenführungen erahnbar, lässt sich aus historischen Quellen, archäologischen und bauhistorischen Befunden bis zu einem gewissen Grad rekonstruieren. ${ }^{170}$

${ }^{168}$ Zur Bédeutung bauhistorischer Befunde für die Sozialgeschichte vgl. Fred KASPAR, Bauund Raumstrukturen städtischer Bauten als sozialgeschichtliche Quelle, dargestellt an bürgerlichen Bauten des 14. bis 18. Jahrhunderts aus Nordwestdeutschland. in: Die Familie als sozialer und historischer Verband. Untersuchungen zum Spätmittelalter und zur frühen Neuzeit, hg. von Peter-Johannes SCHULER. Sigmaringen 1987, S. 165-186; Michael SCHEFTEL, Gänge. Buden und Wohnkeller in Lübeck (Häuser und Höfe in Lübeck 2), Neumünster 1988. S. 61-86; Johannes CRAMER, Handwerkerhäuser im Mittelalter - Zur Abhängigkeit von Handwerk und Beruf, in: Jahrbuch für Hausforschung Bd. 33: Hausbau im Mittelalter, Sobernheim/Bad Windsheim 1983, S. 183-212; Sven SCHÜTTE, Bebauungsstruktur und Sozialtopographie im spätmittelalterlichen Göttingen, in: Jahrbuch für Hausforschung, Sonderband 1988 für Josef Schepers: Hausbau im Mittelalter III, Sobernheim/Bad Windsheim 1988, S. $171-220$.

${ }^{169}$ Vgl. Karl SCHLÖGEL, Im Raume lesen wir die Zeit. Über Zivilisationsgeschichte und Geopolitik, München/Wien 2003, hier vor allem S. 9-15.

${ }^{170} \mathrm{Zu}$ Gestalt der Stadt noch immer grundlegend: Cord MECKSEPER, Kleine Kunstgeschich: 
Auf das Beispiel der Stadt bezogen, bezeichnet „Raum“ hier also nicht nur den Leerraum zwischen den Gebäuden, sondern umfassend Straße, Platz, Haus, die Ausgestaltung der Fassade, ihre Beziehung zu Nachbarhäusern und Straße, die Motivation, die hinter dieser Gestaltung steht, ebenso Kirche, Kapelle, Rathaus, Markt, Stadtmauer - schlicht alle städtischen Elemente. Was mit dem Stadt-Raum beschrieben werden soll, ist aber nicht das Nebeneinander, die Aneinanderreihung dieser Elemente, es ist das Beziehungsgeflecht, das die einzelnen Elemente zur Stadt im zeitlichen Längs- und Querschnitt verknüpft, das der einzelnen Stadt ihr typisches Aussehen verleiht, also auch die Menschen, die bewusst oder unbewusst gestaltend dahinter stehen. Damit ist zugleich angedeutet, dass in diesem Verständnis von Raum eine wesentliche soziale Komponente enthalten ist. ${ }^{171}$

Da sich Sozial- und Verfassungsstruktur in den Stadt-Raum einprägen, werden diese zugleich von ihm widergespiegelt - die städtische Raumstruktur hat so ihren eigenen Quellenwert. Eine Quelle, die, verknüpft mit den schriftlichen Zeugnissen, einen wesentlichen Beitrag zur Rekonstruktion der städtischen Gesellschaft der Vergangenheit leisten kann.

Dies ist nun keineswegs ganz neu. Schon Winfried Schich verband in seiner Arbeit zu Würzburg im Mittelalter die Gestalt der Stadt und die städtische Gesellschaft zu einem Gesamtbild Würzburgs für eine noch quellenärmere Zeit. ${ }^{172}$ Auch Heinrich Rüthing stellte die Bürger und Einwohner Höxters in den Stadtraum um 1500, ${ }^{173}$ und schließlich widmet sich die Lübecker Reihe „Häuser und Höfe" diesen verschiedenen Elementen. ${ }^{174}$ Das Beispiel Lübeck verweist dann auch auf das Problem, um das

te der deutschen Stadt im Mittelalter, Darmstadt 1982; Eberhard ISENMANN, Die deutsche Stadt im Spätmittelalter, Stuttgart 1988: Hartmut BOCKMANN, Die Stadt im späten Mittelal= ter, München ${ }^{3}$ 1994. - Allgemeiner: Wolfgang BRAUNFELS, Abendländische Stadtbaukunst, Köln 1976. - Sehr anregend zu den historischen Bedingungen räumlicher Entwicklung: Rolf HAMMEL-KIESOw; - Lübeck-als Vorbild zahlreicher Städtegründungen im Ostseeraum? (wie Anm. 8). - Zu den Raumbeziehungen und baulichen Elementen des Stadtraums vgl. auch Ernst Schirmacher, Stadtvorstellungen, Zürỉch/München 1988, allerdings kritisch zu lesen, da der Architekt und Städteplaner Schirmacher mitunter zu ahistorischen Erklärungsansätzen neigt.

${ }^{171}$ Vgl. IGEL. Auf der Spur des Stadt-Raums (wie Anm. 43). - Zur Soziologie des Raumes allgemein: Martina Löw, Raumsoziologie, Frankfurt/Main 200I: Pierre BouRdiEU, Physischer, sozialer und angeeigneter physischer Raum, in: Stadt-Räume. Die Zukunft des Städtischen (Frankfurter Beiträge 2), hg. von M. WENTZ, Frankfurt (Main)/New York 1991, S. $25-34$.

${ }^{172}$ Winfried SCHICH, Würzburg im Mittelalter. Studien zum Verhältnis von Topographie und Bevölkerungsstruktur (Städteforschung A 3), Köln/Weimar/Wien 1977.

${ }^{173}$ RÜTHING, Höxter um 1500 (wie Anm. 5).

${ }^{174}$ Vgl. Wege zur Erforschung städtischer Häuser und Höfe (wie Anm. 167); SCHEFTEL, 
es hier im wesentlichen gehen soll. Der Quellenreichtum, sowohl historisch wie archäologisch und bauhistorisch, die Länge des gewählten Zeitraums und nicht zuletzt die schlichte Größe dieser Ostseestadt machen es unmöglich, eine bis in einzelne Details gehende Untersuchung innerhalb eines: überschaubaren Zeitraums abzuschließen, schon gar nicht durch einen einzelnen Bearbeiter. Zugleich stellt sich aber auch die Frage, wie sich Städte mit einer anders gearteten oder auch schlechteren Quellenlage untersuchen und miteinander vergleichen lassen.

\subsection{Lübische Stadtbücher und Stadt-Raum}

Bereits im Blick auf die Greifswalder Überlieferung wurde auf die Bedeutung der Stadtbücher hingewiesen. Unter dem Begriff „Stadtbuch“ werden hier gemäß der Definition Wilhelm Ebels jene städtischen Quellen zusammengefasst, die der Aufzeichnung privater Rechtsgeschäfte dienten und durch den vom Rat abgesicherten Eintrag als besonderes Beweismittel im Rechtsverkehr dienen konnten. ${ }^{175}$ Erfasst werden damit auch jene Bücher, in die Veräußerungen, Verpfändungen und Rentenbelastungen von Grundstücken eingetragen wurden, die also im modernen Verständnis Grund- und Hypothekenbüchern entsprechen. Erhalten sind Stadtbücher dieser Art noch in großer Fülle. ${ }^{176}$

Liegt ein durchaus nicht geringer Teil dieses Quellenmateriales sogar in edierter Form bereit, so steht, von Lübeck ${ }^{177}$ und Greifswald ${ }^{178}$ abgesehen, eine umfassende Auswertung unter sozialgeschichtlichen, insbesondere auch sozialtopographischen Aspekten noch weitgehend aus. Aus der Auswertung ergeben sich zunächst Eigentumsgeschichten für die einzelnen Grundstücke. So ist zuerst nach den Möglichkeiten und Grenzen einer solchen Eigentumsgeschichte zu fragen. Zweifellos bildete Grundeigentum einen wesentlichen Faktor wirtschaftlichen Handelns in der Stadt und somit auch innerhalb des gesellschaftlichen Geflechtes. Grundeigentum konnte eine wesentliche Einnahmequelle sein, als Sicherheit für eine Handelstätigkeit dienen oder schlicht den Raum für eine gewerbliche

Gänge, Buden und Wohnkeller (wie Anm. 168); Claus VelTMANN, Knochenhauer in Lübeck am Ende des 14. Jahrhunderts (Häuser und Höfe in Lübeck 3.1), Neumünster 1993; Ausstattungen Lübecker Wohnhäuser. Raumnutzungen, Malereien und Bücher im Spätmittelalter und der frühen Neuzeit (Häuser und Höfe in Lübeck 4), hg. von Manfred EICKHÖLTER und Rolf HAMMEL-KIESOW, Neumünster 1993.

${ }^{175}$ Vgl. EBEL. Lübisches Recht (wie Anm. 3), S. 427-438.

${ }^{176} \mathrm{Vgl}$. die Übersicht bei ebd., S. 417-427.

${ }^{177}$ Hammel, Hauseigentum (wie Anm. 1); HAMmel-Kiesow, Quellen und Methoden (wie Anm.161).

${ }^{178}$ IGEL, Greifswalder und Greifswald um 1400 (wie Anm. 4). 
Tätigkeit bieten. Zugleich konnte es aber auch das Ergebnis erfolgreichen wirtschaftlichen Handelns bilden, wie es wohl für das Beispiel des Greifswalder Krämers Peter von Eventure angenommen werden kann. Die Motivation zum Grunderwerb dürfte zudem in einer Abhängigkeit von der ausgeübten Tätigkeit stehen. Damit deutet sich aber schon cine Grenze der Betrachtung an, denn die Schaffung von Grundeigentum war Teil eines Prozesses und folglich der Übergang zwischen Eigentumslosen und Eigentümern fließend, hier wäre zum Beispiel an die ersten beiden Generationen der Familie Slupwachter zu denken. Die Schicht der Eigentumslosen bleibt in einer auf dem Grundeigentum als sozialen Faktor aufbauenden Untersuchung natürlich weitgehend unberücksichtigt. Einzelne Personen können aber zu unterschiedlichen Zeitpunkten den beiden verschiedenen Gruppen angehört und mehrfach die Scheidelinie dazwischen überschritten haben. Das Ergebnis der Betrachtung hängt damit wesentlich von dem zeitlichen Rahmen ab, den der jeweilige Betrachter wählt.

Ist schon der Übergang zwischen diesen beiden Gruppen unscharf, so ist ihr zahlenmäßiges Verhältnis in der mittelalterlichen Stadt bislang kaum festzulegen. Nach Region, Größe und gewerblichen Schwerpunkten werden sich diese zudem mehr oder weniger stark unterschieden haben. Dabei lässt sich, wie angedeutet, nicht einmal sicher festlegen, ob die Grenze zwischen Eigentümern und Eigentumslosen zugleich auch immer eine soziale Scheidelinie bedeutete, denn neben dem Erwerb von Grundeigentum bot sich auch der städtische Rentenmarkt zur finanziellen Betätigung und Absicherung an. Der Mieter eines Hauses in einer zentralen Straße verfügte zudem über ein besseres Lebensumfeld als der Eigentümer einer Bude in städtischen Randbereichen, entsprechende Beispiele lassen sich aus den Stadtbüchern erschließen. So kann in der zweiten Hälfte des 14. Jahrhunderts in Greifswald ein Ratsherr Wichard Vredeland nachgewiesen werden, der zwar zum Zeitpunkt seiner Wahl Grundeigentümer war, aber den längsten Teil seiner 48-jährigen Amtszeit über kein Grundeigentum verfügte und in einem städtischen Haus zur Miete .wohnte. ${ }^{179}$ Gleiches kann auch in Kolberg beobachtet werden, ${ }^{180}$ während in Lübeck auf den Verlust des Grundeigentums in der Stadt auch der Verlust des Ratssitzes folgte. ${ }^{181}$

\footnotetext{
${ }^{179}$ Vgl. ebd., S. 233 f.

${ }^{180}$ Vgl. Peter TEPP, Untersuchungen zur Sozial- und Wirtschaftsgeschichte der Hanse- und Salzstadt Kolberg im Spätmittelalter. Strukturwandel und soziale Mobilität. Diss. phil. Hamburg 1980, S. 223 f. Tab. DI7.

${ }^{181}$ Vgl. Michael LUTTERBECK, Der Rat der Stadt Lübeck im 13. und 14. Jahrhundert. Politische, personale und wirtschaftliche Zusammenhänge in einer städtischen Führungsgruppe (Veröffentlichungen zur Geschichte der Hansestadt Lübeck B/39), Lübeck 2002, S. 143f.; EBEL, Lübisches Recht (wie Anm. 3), S. 225.
} 
Vom Grundeigentum ausgehend, sind daher weitere Gesichtspunkte zu berücksichtigen. Wo vollständige Verzeichnisse bestimmter Gruppen (Handwerkerämter) zur Verfügung stehen, muss nach dem Anteil der Grundeigentümer gefragt werden und nach der Zeitspanne in der sie jeweils über Immobilien verfügten. $\mathrm{Zu}$ fragen ist auch nach den Unterschieden in der Beteiligung verschiedener Gruppen am Grundstücksmarkt und ob diese sich aus den unterschiedlichen Erfordernissen einer gewerblichen Tätigkeit begründen lassen, also nicht notwendig auf wirtschaftliche Unterschiede schließen lassen. In diesem Zusammenhang sollten die Eigentumslosen auf ihre Beteiligung am Rentenmarkt und andere finanziellen Betätigungen untersucht werden, insofern die Quellenlage es zulässt. Der Idealfall bestünde dann, wenn Steuerverzeichnisse mehrerer Jahre mit den Vorgängen auf dem städtischen Grundstücksmarkt verglichen werden könnten. Unter den oben angeführten Städten scheint dieses allein für Rostock möglich zu sein, wo einzelne Schoßregister ab 1342 und seit 1378 dann weitgehend lückenlos überliefert sind. ${ }^{182}$

Eine Sozialgeschichte des Grundeigentums muss also das topographische Element mit dem biographischen zu einem Strang verknüpfen. Zur Topographie gehört dabei die Rekonstruktion des mittelalterlichen-Grundstücksgefüges samt der sich wandelnden Besitzverhältnisse, also der Grundstücksbiographie jeder Parzelle. Die Grundstücksbiographie erstreckt sich so in einer räumlichen und einer zeitlichen Dimension. Zugleich können auf diese Weise städtische Einwohner oder Familien biographisch in der zeitlichen Veränderung ihres Grundbesitzes und dessen räumlicher Verteilung innerhalb der städtischen Topographie betrachtet werden. Zentral sind dabei die Fragen, wann jemand Grundbesitz erwarb (oder veräußerte), wo dieser in der Stadt lag und woraus sich Anlass und topographische Lage begründeten.

Damit wäre zugleich ein nächster wichtiger Aspekt angesprochen. Die Untersuchung muss einen längeren Zeitraum umfassen, der über mehr als eine Generation reichen sollte. Denn ein Querschnitt durch die Stadt und ihre Bevölkerung in einem bestimmten Stichjahr mag ein schönes Überblicksbild gewähren, würde wie bei den Steuerverzeichnissen zugleich aber auch zu statische Verhältnisse suggerieren. Ein der historischen Wirklichkeit nahe kommender (sozial-)topographische Plan der Stadt kann sich aber erst dann wirklich entfalten, wenn sich zwischen den statischen und den sich mehr oder minder beständig wandelnden Elementen unterscheiden lässt und diese zu einem Bild verknüpft werden. Erst darin drücken

${ }^{182}$ Vgl. SChILdHaUeR, Die Sozialstruktur der Hansestadt Rostock (wie Anm. 53), S. 342. 
sich soziale Prozesse im Stadt-Raum aus. Gleiches gilt natürlich auch für den einzelnen Grundeigentümer in der Stadt: interessant ist nicht allein, wie viel er zu einem bestimmten Zeitpunkt besaß, sondern, wann er Eigentum erstmals erwarb, wann es sich vermehrte oder verminderte und welche Motivation dahinter stand bzw. vermutet werden kann. ${ }^{183}$

\subsection{Bauliche Gestalt und soziale Struktur}

Die Einträge in den Stadtbüchern verzeichnen aber nicht nur die am Grundstücksgeschäft beteiligten Personen und die Lage des betroffenen Objektes, sie beschreiben dieses auch häufig detaillierter, um die genaue Identifizierung sicherzustellen. Gegenüber der üblichen Bezeichnung als domus oder hereditas finden sich so Differenzierungen, die ein Gebäude als traufenständig, als hölzern oder steinern oder aber als Bude bezeichnen. ${ }^{184}$ Daneben finden sich Sonderbauten wie Schmieden, Backhäuser (bei deren Nennung auch die Feuergerechtigkeit eine Rolle spielt), Getreidespeicher, Scheunen, Ställe u.ä. Die Erwähnung solcher Baubeschreibungen ist dabei natürlich zufällig. Einerseits musste überhaupt ein entsprechendes Rechtsgeschäft erfolgen und andererseits musste es dem Schreiber auch als sinnvoll erscheinen, eine genauere Differenzierung vorzunehmen. So konnten zwischen der Errichtung einer steinernen Straßenfassade und der Nennung des Gebäudes im Stadtbuch als steinern Jahrzehnte liegen. Auf das einzelne Objekt bezogen, ist der Informationswert also vorsichtig zu bewerten. Eine vollständige Auswertung über einen längeren Zeitraum zeigt aber Schwerpunktbildungen auf - vor allem auch jene Bereiche, in denen sich die frühesten Erwähnungen häufen. Für den in Greifswald untersuchten Zeitraum zwischen 1350 und 1450 ergibt sich ein eindrucksvolles Bild (Abb. 1). Die nachweisbaren Steinhäuser konzentrieren sich in erster Linie auf den Markt und die von diesem zum Hafen führenden Straßen. Knopf-, Büch- und Fischstraße, ${ }^{185}$ in den angrenzenden Abschnitten nimmt die Zahl bereits deutlich ab. Der westliche Teil der Stadt - die Neustadt - bleibt fast gänzlich unberührt.

\footnotetext{
${ }^{183}$ So auch HaMmEL, Hauseigentum (wie Anm. 1), S. 125.

${ }^{184} \mathrm{Zu}$ den Bezeichnungen vgl. Rolf HAMMEL, Hereditas, area und domus: Bodenrecht, Grundstücksgefüge und Sozialstruktur in Lübeck vom 12. bis zum 16. Jahrhundert, in: Jahrbuch für Hausforschung 35: Hausbau in Lübeck. Mit Beiträgen zum Hausbau in Hamburg, Lüneburg und Mölln. Sobernheim 1986. S. 175-199; DERS., Hauseigentum (wie Anm. 1), S. 101 f.; IGEL, Greifswalder und Greifswald um 1400 (wie Anm. 4), S. 73 f.

${ }^{185}$ Dieser Bereich, vor allem Großer Markt, Fisch- und Knopfstraße, hebt sich durch besonders frühe Erwähnungen von Steinhäusern noch zusätzlich ab, vgl. IGEL, Greifswald um 1400 (wie Anm. 4), S. 33, Abb. 4.
} 
Buden als kleinräumigere Wohnbauten ${ }^{186}$ sind in Greifswald war allem dort zahlreich, wo die Steinhäuser fehlen, oder stehen in den Quer- und Nebenstraßen, wo sie zum Teil als rückwärtige Bauten zu den Grundstükken an den Hauptstraßen gehörten. Sie konzentrieren sich auf die westliche Altstadt, die Neustadt und entlang der Hafenmauer. Daneben finden sich Buden südlich des Marktes in der Fleischerstraße auch als Hökerbuden mit gewerblicher Funktion. Die eingezeichneten Traufenhäuser sind in ihrem baulichen Spektrum anscheinend etwas weiter gefasst, einerseits kommt es zum Teil zur begrifflichen Überlagerung mit Budenkomplexen, die ja in aller Regel auch traufenständig zur Straße standen, andererseits verbergen sich hinter den als steinern bezeichneten Traufenhäusern zum Teil besonders herausragende Bauten. So sind die beiden benachbarten, heute neuzeitlich überformten Häuser Fischstraße 17 und 18 in unmittelbarer Nähe zum Markt noch in wesentlichen Relikten erhalten. Das ältere der beiden, die Hausnummer 18, wurde nach den bauhistorischen Untersuchungen zwischen 1285 und 1290 errichtet und verfügte ursprünglich über einen freien Schaugiebel nach Norden in Richtung Hafen hin. ${ }^{187}$ Dieser verschwand mit dem Bau des nördlich anschließenden Traufenhauses Fischstraße 17 um die Mitte des 14. Jahrhunderts. Letzteres wurde bereits 1353, also relativ bald nach der Errichtung, im Greifswalder Stadterbebuch als hereditas transversalis lapidea bezeichnet, ${ }^{188}$ während der ältere Bau erst 1380, also fast ein Jahrhundert nach der Errichtung, im Stadtrentenbuch als solche beschrieben wurde. ${ }^{189}$ Auf die Entstehungszeit lässt sich aus solchen Einträgen also nicht schließen. Ähnlich auffällige Bauten zeichnen sich auf der Südseite des Großen Marktes ab. Die Ausmaße dieser Häuser, an deren Stelle Ende des 19. Jahrhunderts das Postamt errichtet wurde, sind noch auf der schwedischen Matrikel von $1707^{190}$ und auf einem um 1850 entstandenen Stich (Abb. 5) erkennbar.

Bemerkenswert sind zudem die zahlreichen Höfe, Großgrundstücke, die sich aus verschiedenen Baukörpern zusammensetzten und überwiegend im Gebiet südlich von St. Nikolai und St. Jakobi sowie am westlichen und östlichen Rand der Stadt lagen. Nach einzelnen Beschreibungen befand sich das eigentliche Hauptgebäude hier abseits der Straße, an der dagegen Buden oder andere Nebengebäude standen. Dieses „Abrücken“ vom

\footnotetext{
${ }^{186} \mathrm{Zu}$ den Buden als Bauform vgl. SCHEFTEL, Gänge, Buden und Wohnkeller (wie Anm. 168), S. 6-41.

${ }^{187}$ Dieser Giebel ist noch im Treppenhaus des nördlich gelegenen Hauses Fischstraße $17 \mathrm{zu}$ erkennen.

${ }^{188}$ IGEL, Greifswalder und Greifswald um 1400 (wie Anm. 4), Regest 5101.

${ }^{189} \mathrm{StAG}$, Rep. $3 \mathrm{Nr} .15, \mathrm{f} 136 \mathrm{r}$.

${ }^{190}$ Die Schwedische Landesaufnahme von Vorpommern 1692-1709 (wie Anm. 26); vgl. auch IGEL, Greifswald um 1400 (wie Anm, 4), S. 23, Abb. 1.
} 


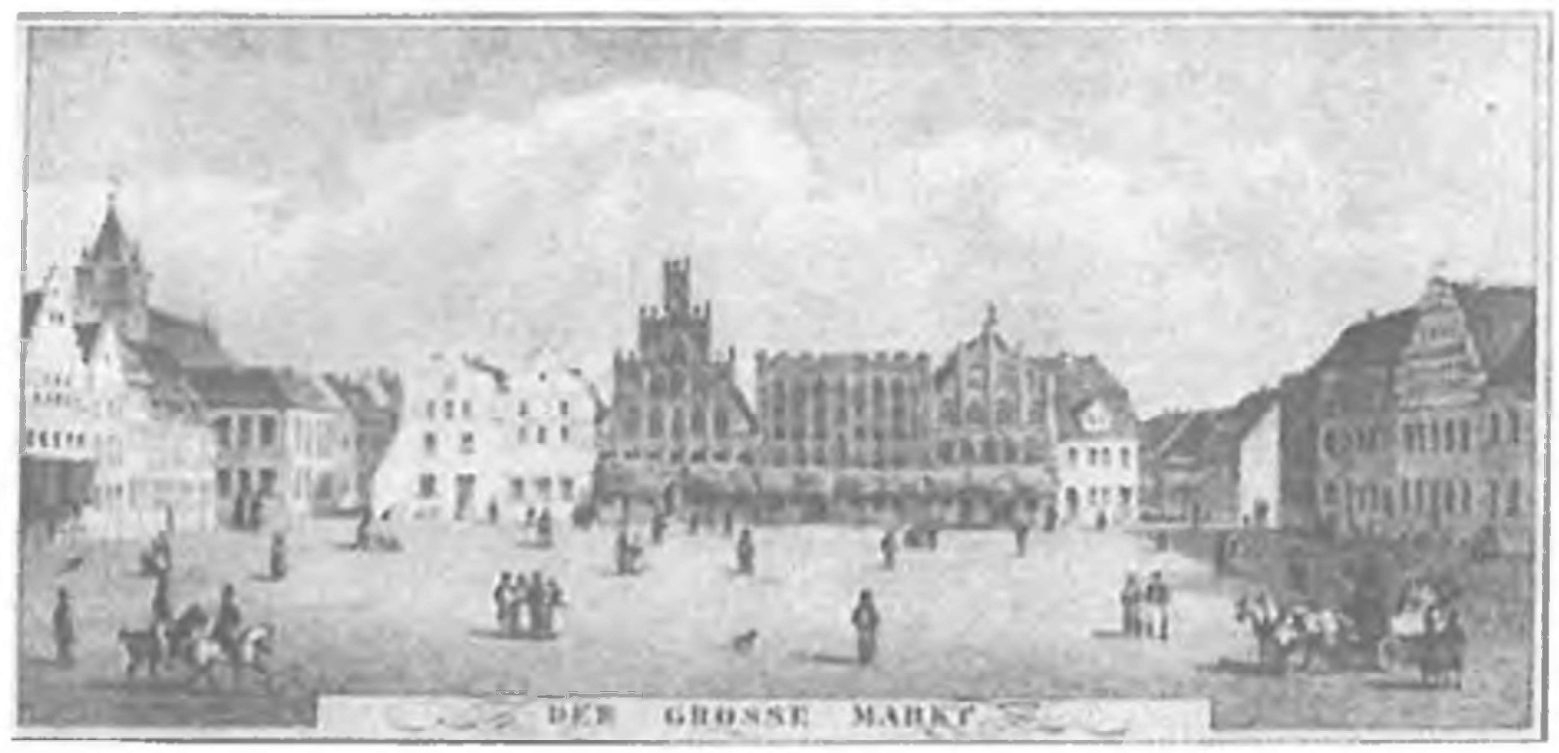

Abb. 5: Greifswald, Großer Markt nach Osten um 1850

öffentlichen Raum steht in einem starken Gegensatz zu den großen steinernen Giebelhäusern, die mit ihren Fassaden unmittelbar an die Straßen und den Markt grenzten Zum Teil gehörten diese als Nebenbesitze zum Eigentum von Ratsfamilien und anderen wohlhabenden Einwohnern. Einer dieser Höfe in der Nähe von St. Jakobi diente allerdings mehreren Generationen der Bürgermeister- und Ratsherrenfamilie Letzenitze als Wohnsitz. ${ }^{191}$

Der Verteilung der Steinhäuser entspricht auch die Lage der für das Jahrhundert zwischen 1350 und 1450 nachweisbaren Wohnhäuser der Greifswalder Ratsherren. Diese konzentrieren sich auf den Markt und die von diesem zum Hafen führenden Straßen, in aller erster Linie auf die Knopfstraße und den östlichen Teil des Marktes (Abb. 6). Ein Blick auf den Grundbesitz von Hökern und verschiedenen Handwerkern zeigt ebenfalls bestimmte Schwerpunktbildungen (Abb. 7): ${ }^{192}$ südlich des Marktes vor allem Höker, aber auch verschiedene andere Gewerbe in den Hökerbuden links und rechts der Hökerstraße, zahlreiche Knochenhauer rund um den zwischen Fleischer- und Kuterstraße gelegenen Fleischscharren, ${ }^{193}$ in Ecklagen hier auch einige Bäcker. Im nördlichen Teil der Büchstraße, nahe am Hafen, eine Konzentration von Böttchern, die sich in geringerer Zahl auch an Brügg- und Kuhstraße finden. Stark handwerklich geprägt ist der Bereich zwischen Fischstraße und Kapaunstraße, ein Teil der Stadt,

${ }^{191} \mathrm{Vgl}$. IGEL, Greifswald um 1400 (wie Anm. 4), S. 37-42; ähnliche Strukturen fanden sich in Lübeck um St. Ägidien, vgl. HAMmEL-KIESOW, Entstehung des sozialräumlichen Gefüges (wie Anm. 5).

192 Vgl. IGEL, Greifswalder und Greifswald um 1400 (wie Anm. 4), S. 362-375.

${ }^{193} \mathrm{Zu}$ den Markteinrichtungen vgl. IGEL. Greifswald um 1400 (wie Anm. 4), S. 26-31. 


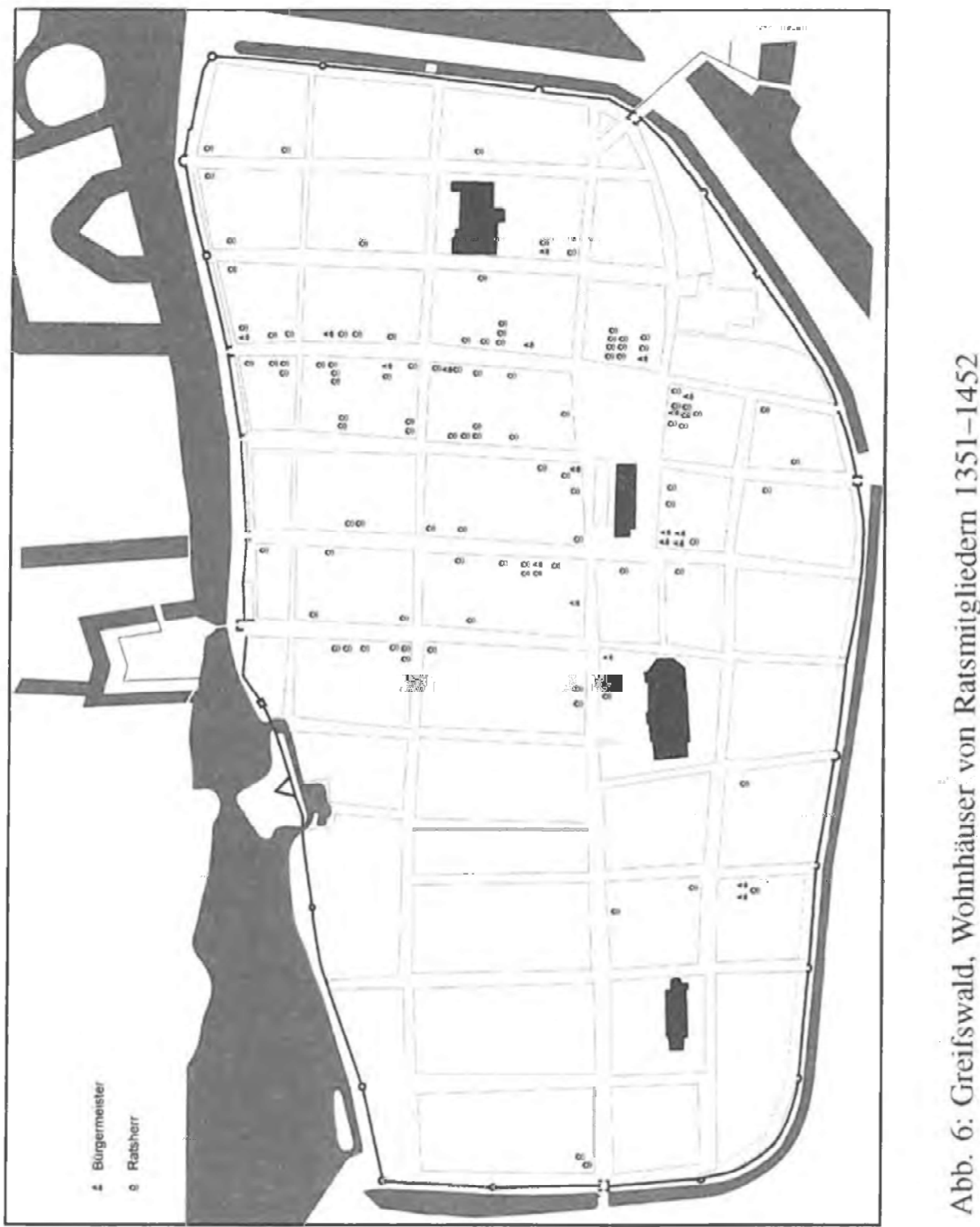

der sich auch in seinen baulichen Strukturen von dem Gebiet zwischen Markt und Hafen unterschied. Besonders auffällig sind die Ansammlung von lederverarbeitenden Gewerben im Bereich um Rot- und Weißgerberstraße sowie die Konzentration der Wollweber auf die Kapaunstraße, die sich auch aus deren Amtsstatuten belegen lässt. ${ }^{194}$ Weitgehend frei von nachweisbaren Gewerben bleiben dagegen der östliche Teil des Marktes

${ }^{194}$ Vgl. Krause/KunZe, Zunfturkunden 2 (wie Anm. 18), S. 151-153. 


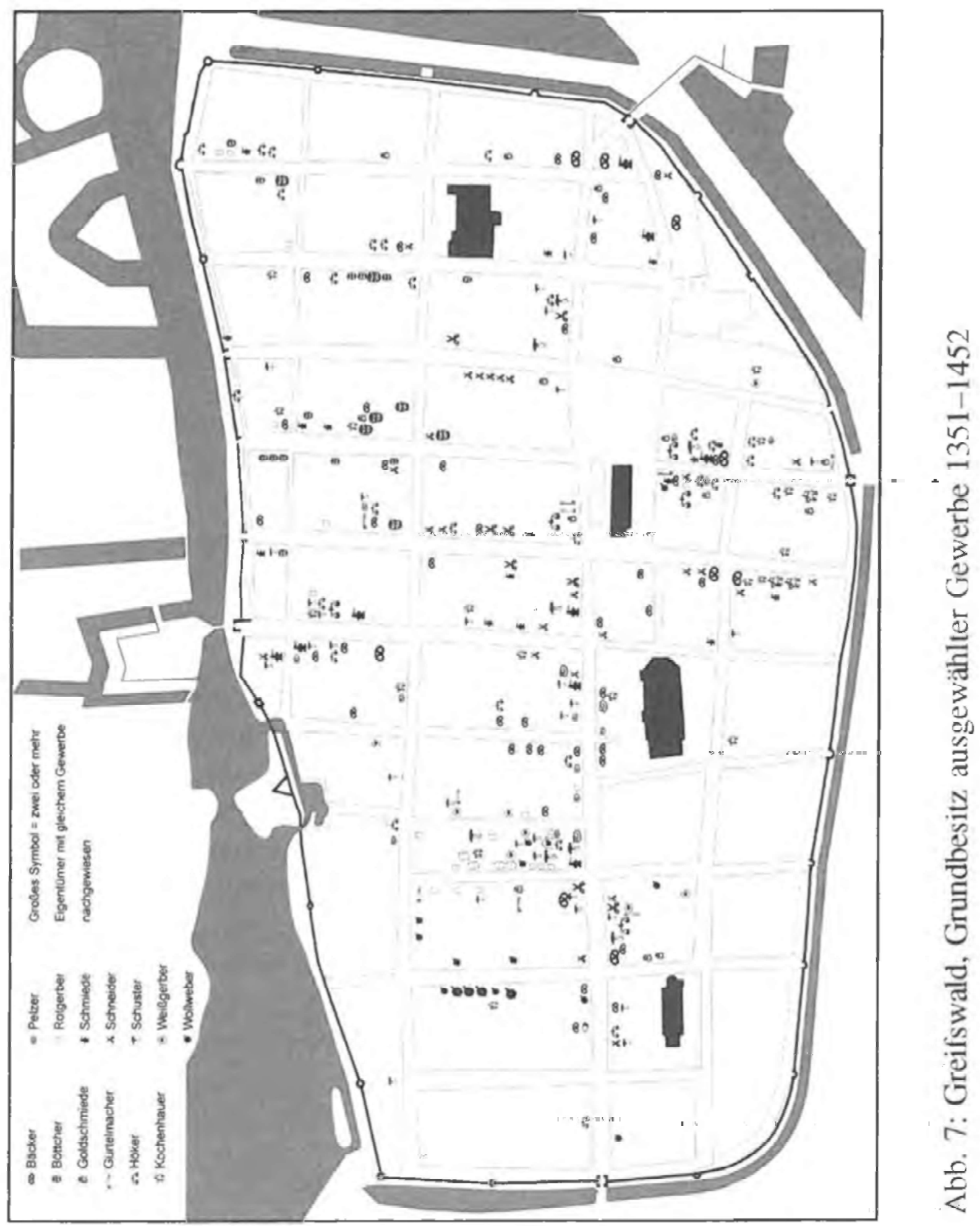

und die Knopfstraße, also der bevorzugte Wohnbereich der ratsherrlichen Familien. Hier kann fast nur für Schneider, die zusammen mit Pelzern, Schmieden und Schustern als sogenannte Vier-Gewerke die führenden Handwerksämter Greifswalds bildeten, Grundbesitz nachgewiesen werden. Praktisch frei blieb ebenfalls die Stremelower Straße am westlichen Rand der Stadt und der Bereich südlich von St. Jakobi und St. Nikolai. Anzumerken bleibt allerdings, dass hiermit eben nur jene Mitglieder dieser gewerblichen Gruppen abgebildet werden, die zumindest zeitweilig ein 


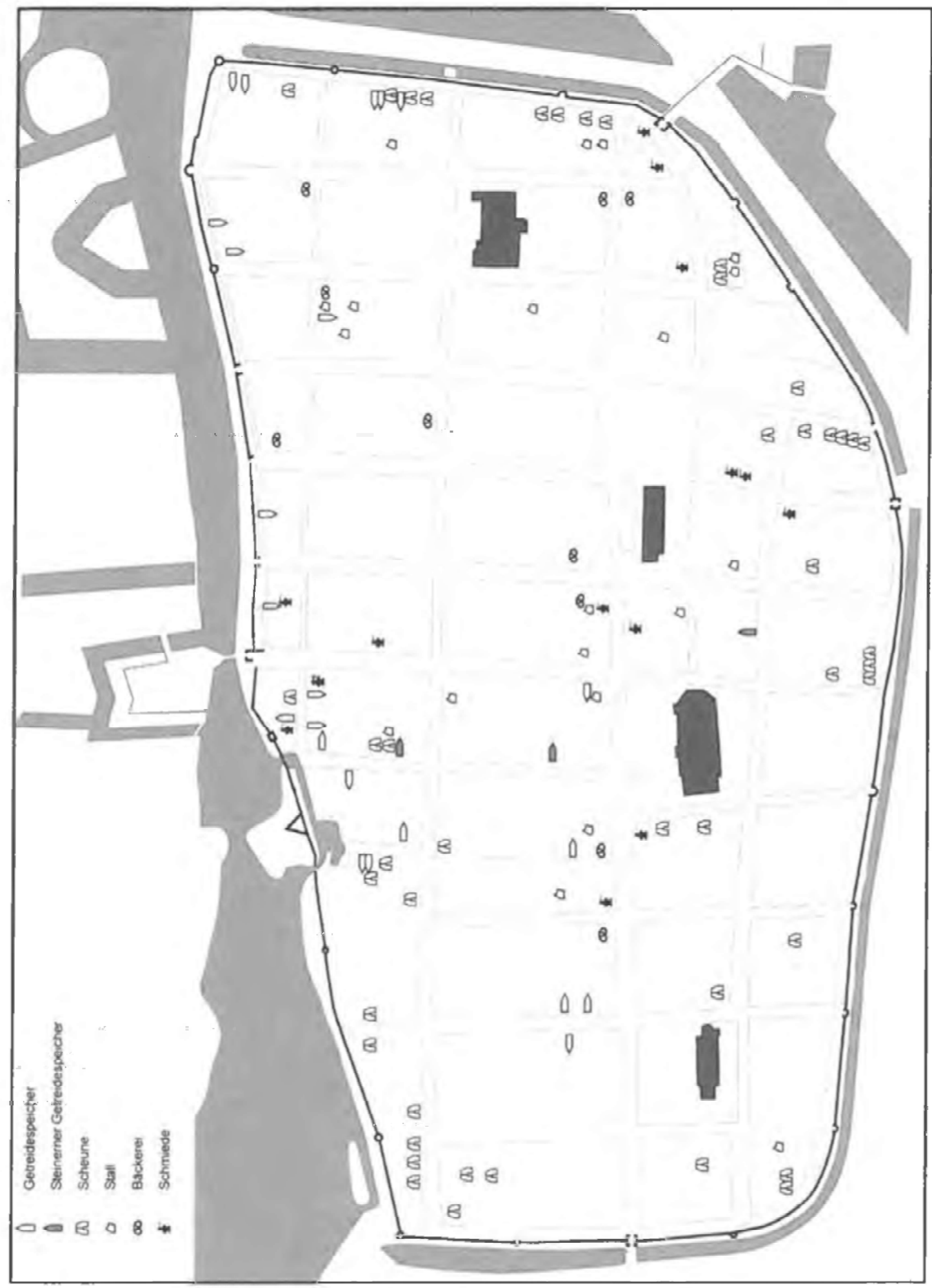

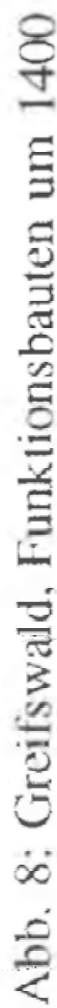

Haus in der Stadt besaßen, und diese waren nicht selten in der Minderheit. Während $60 \%$ der zwischen 1365 und 1381 tätigen Wollweber Grundbesitz erwarben, waren es bei den Hökern und Schustern, für die 1375 bzw. 1376 Verzeichnisse in das Kämmereibuch eingetragen wurden, weniger als ein Drittel. ${ }^{195}$

${ }^{195}$ Vgl. IGEL, Greifswalder und Greifswald um 1400 (wie Anm. 4), S. 358-361. 
Auch für Funktionsbauten lassen sich spezifische Verteilungen im Stadtraum erkennen (Abb. 8). Getreidespeicher am und in der Nähe des Hafens, rund um die städtische Wassermühle am Ryck, aber auch in Orientierung auf die Lange Straße. Scheunen in einer vergleichbaren Lage wie die Höfe, zum Teil gehörten sie als Elemente auch zu diesen. Ställe zum Teil auch als Hinterhofbauten in zentraleren Bereichen der Stadt. Für die Schmieden fällt in erster Linie eine Ausrichtung auf den Markt und drei der vier Landtore, Fleischertor, Mühlentor und Steinbecker Tor auf. Die nachweisbaren Bäckereien liegen wie die Schmieden bis auf eine Ausnahme in der Altstadt in einer vergleichsweise gleichmäßigen Verteilung, überwiegend auf Eckgrundstücken oder daran anschließenden Parzellen. Beide Bauformen decken sich in ihrer Verteilung mit den Befunden zu den entsprechenden Handwerken.

Für Greifswald kann so aus den Schriftquellen ein Bild der räumlichen Verteilung von unterschiedlichen Bebauungsstrukturen rekonstruiert werden, zudem aus Quellen, die für den untersuchten Zeitraum praktisch lükkenlos sind. Die Grenzen liegen nur in der Häufigkeit und Genauigkeit der -Nenntug sowie der zeitlichen Differenz zwischen Errichtung und erster Nennung. Zugleich können diese Befunde unmittelbar bestimmten Personen (auch in der Dauer des Besitzes) zugeordnet werden und jene auch in zahlreichen Fällen - für den Greifswalder Rat lückenlos - einer bestimmten Sozialgruppe zugewiesen werden. In jedem Fall lassen sich aber Aussagen über Umfang, Dauer und zeitlichen Verlauf des jeweiligen Grundbesitzes treffen - und dies eben auch im Blick auf bestimmte Sozialgruppen.

Auch für Osnabrück besteht für das 14. und besonders das 15. Jahrhundert eine sehr umfangreiche Überlieferung zu Grundstücksgeschäften allerdings in urkundlicher Form, so dass hier kein geschlossener Bestand vorliegt. Die Lücken sind natürlich groß und in ihren Ausmaßen auch nur begrenzt abzuschätzen, da die Chancen der Überlieferung weitgehend zufällig waren. ${ }^{196}$ Aber eben auch nur weitgehend, denn Urkunden, die Stiftungen zu städtischen Hospitälern oder deren Grundbesitz betrafen, blieben in der Regel erhalten, so dass sich hier zu einzelnen Grundstücken sogar mehrere Rechtsgeschäfte finden. Ähnliches gilt auch für kirchliche Einrichtungen, soweit sie die Reformation überstanden. Für eine topographische Rekonstruktion ergeben sich daraus zumindest Ankerpunkte, an die sich mitunter weitere Grundstücksgeschäfte räumlich anknüpfen lassen. Eine lückenlose Rekonstruktion bzw. eine genaue Zuweisung einzelner genannter Grundstücke dürfte sich allein aus dieser urkundlichen

${ }^{196} \mathrm{Vgl}$. IGEL, Auf der Spur des Stadt-Raums (wie Anm. 43), S. 151. 


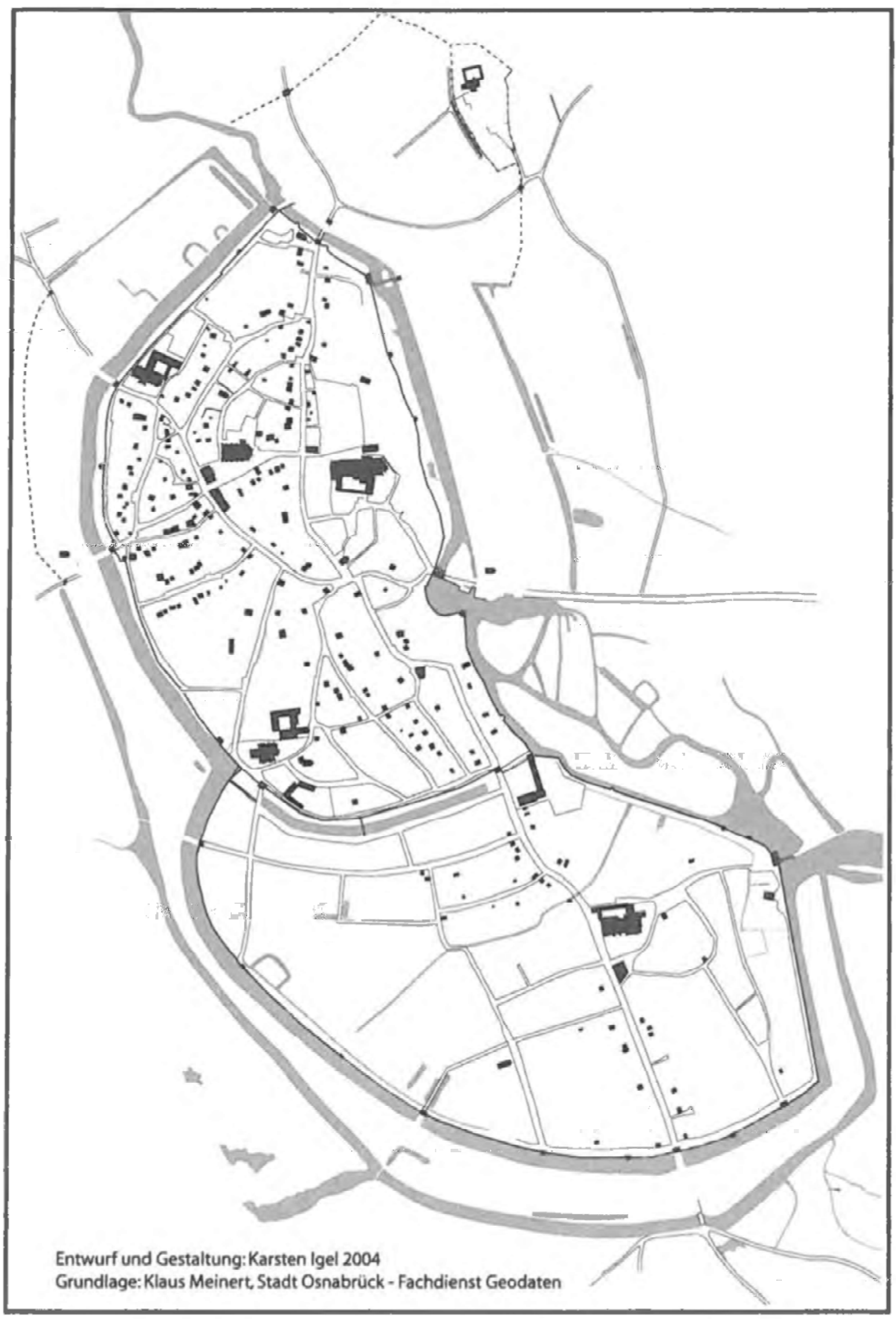

Abb. 9: Osnabrück, nachgewiesene Steinwerke 
Überlieferung nicht erreichen lassen - auch die fast vollständige Überlieferung von Grundstücksgeschäften (einschließlich Renten) für Greifswald zwischen 1350 und 1450 reichte in einigen Fällen gerade aus, um zu sicheren Aussagen zu gelangen. ${ }^{197}$

Nun bietet sich aber für Osnabrück ab der Mitte des-15. Jahrhunderts eine Verknüpfung mit den verschiedenen Renten- und Einnahmeregistern sowie den bereits erwähnten Steuerverzeichnissen an. Allein das Rentenregister des Johannis-Stiftes führt seit 1435 gut ein Viertel aller Grundstücke in der Neustadt auf, hinzu kommt noch eine größere Zahl in der Altstadt. Wie die Aufzeichnungen zu Grundstücksgeschäften führen auch die Rentenregister in aller Regel Eigentümer und nicht die Bewohner eines Hauses auf - diese höchstens und selten nur zusätzlich. Auf dieser Quellenbasis, die sich über eine Datenbank verknüpfen lässt, ${ }^{198}$ erscheint eine ausreichend genaue Zuordnung innerhalb der Straßen möglich.

Beschreibungen der Bauformen finden sich nicht nur in den Urkunden der Grundstücksgeschäfte, auch die Register liefern zum Teil Hinweise auf Bebauungsstrukturen (Steinwerke und Gademe/Buden), die Steuerverzeichnisse von 1447 und 1463 nennen zudem die Häusler, die zur Miete mit in einem Lauskopaplex lebten, und verweisen so auch auf die Wohndichte. ${ }^{199}$

Genau lokalisieren lässt sich eine große Zahl von Steinwerken, auch wenn diese überwiegend nicht mehr oder nur noch in Relikten bestehen. Nach derzeitigem Stand können noch 136 Steinwerke sicher nachgewiesen werden, hinzu kommen weitere 94, die nach den Befunden aus Bauakten, alten Abbildungen und Karten wahrscheinlich als solche identifiziert werden können. ${ }^{200}$ Im Blick auf die räumliche Verteilung liegt der Schwerpunkt deutlich in der Altstadt, wobei das Gebiet der Domimmunität und der Bereich um St. Katharinen kaum oder nur sehr wenige Steinwerke aufweisen. Besonders dicht belegt ist das Gebiet zwischen Dielingerstraße und Hasestraße. Im Vergleich dazu bleibt die Neustadt stark zurück. Die nachweisbaren Steinwerke beschränken sich weitgehend auf die Johannisstraße, nur Rosen- und Kampstraße weisen noch eine nennenswerte Anzahl auf (Ább. 9).

\footnotetext{
${ }^{197}$ Vgl. IGEL, Greifswalder und Greifswald um 1400 (wie Anm. 4), S. 88-91.

${ }^{198}$ Einzelne Steuerregister wurden vom Verf. bereits erfasst, eine Datenbank zur Aufnahme der Urkunden wird, orientiert an den Erfahrungen mit dem Greifswalder Stadterbebuch, zur Zeit entwickelt.

${ }_{199}$ Vgl. Hildegard DITT, Ältere bevölkerungs- und sozialstatistische Quellen in Westfalen Methoden der Auswertung, in: Voraussetzungen und Methoden geschichtlicher Städteforschung, hg. von Wilfried EHBRECHT (Städteforschung A/7), Köln/Wien 1979. S.-111-128, hier S. 116.

${ }^{200} \mathrm{Vgl}$. Switala, Die Osnabrücker Steinwerke (wie Anm. 51), S. 134.
} 


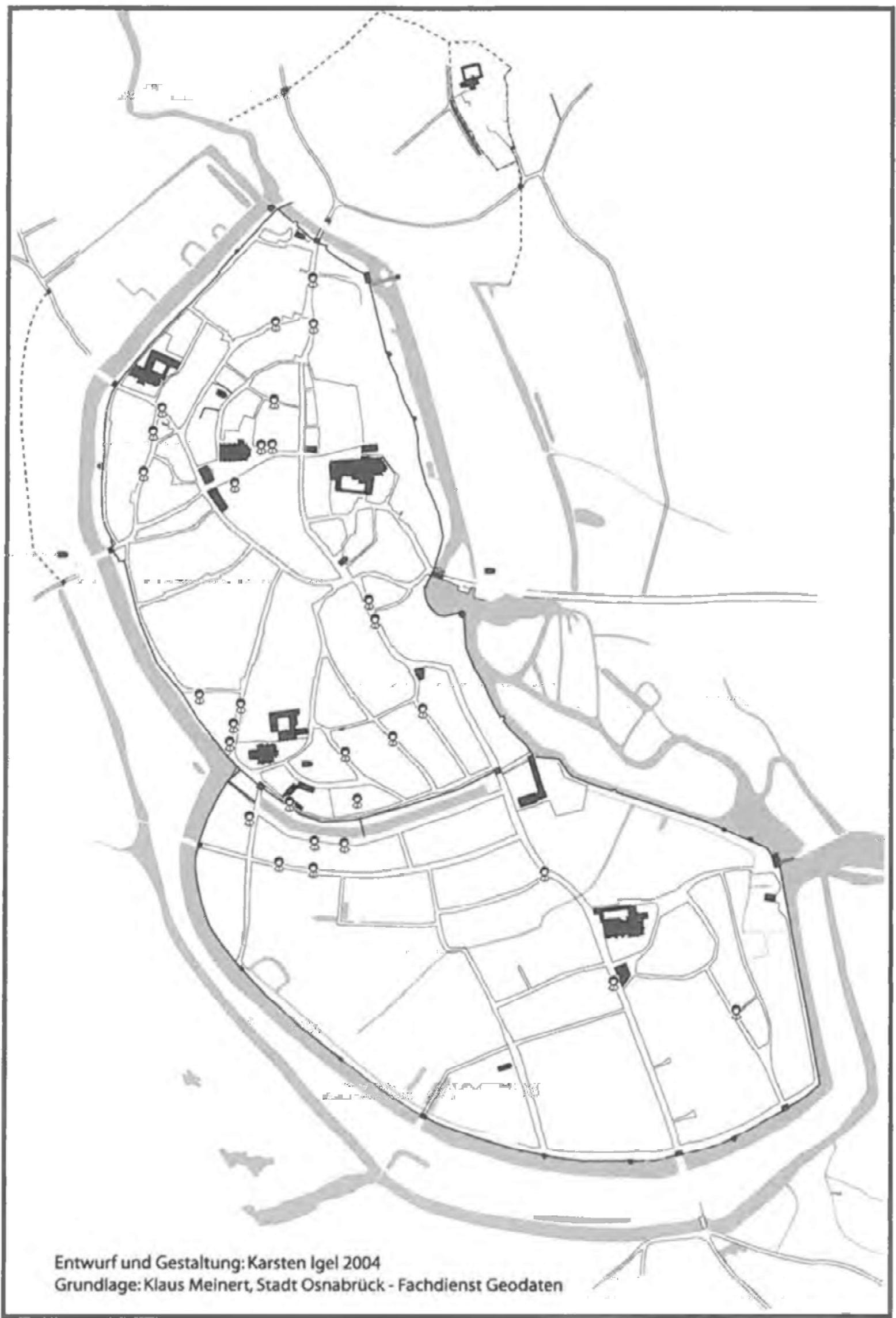

Abb. 10: Osnabrück, Wohnorte von Ratsmitgliedern um 1447 
Die Interpretation dieses Befundes vor dem Hintergrund einer Sozialtopographie erweist sich aber als weniger eindeutig, als auf den ersten Blick zu vermuten. Ein Vergleich mit den Steuerverzeichnissen von 1463 und 1487 zeigt, dass gerade im Bereich um St. Katharinen und im anschließenden nordwestlichen Teil der Neustadt eine größere Zahl wohlhabender Personen lebte. ${ }^{201}$ Auch die Kartierung der Wohnhäuser der in den Jahren um 1447 amtierenden Ratsherren zeigt für diese ein räumliches Schwergewicht im Gebiet um die Katharinenkirche - ebenso für die Ratsherren der Neustadt (Abb. 10). ${ }^{202}$ Die Erklärung für das weitgehende Fehlen von Steinwerken findet sich allerdings in der weiteren Entwicklung dieses Bereiches. Im nordwestlichen Teil der Neustadt entstand nach dem dreißigjährigen Krieg das Stadtschloss der Osnabrücker Bischöfe, so dass dieses Gebiet völlig umgestaltet wurde und keine Spuren der früheren Bebauung erhalten blieben. In den anschließenden Straßen der Neustadt (Kampstraße und Neuer Graben) und der Altstadt (Hakenstraße) entstanden in der Folge vermehrt Stadthöfe des ländlichen Adels, ${ }^{203}$ die auch hier zu einer baulichen Umgestaltung des Stadtraums führten. Gerade die sozial herausgehobene Position dieses Gebietes führte also zum Nichterhalt von Steinwerken, während in den übrigen Teilen der Altstadt die baulichen und sozialen Strukturen bis in das 19. Jahrhundert eher stabil blieben. ${ }^{204}$

Zugleich war Steinwerk aber auch nicht gleich Steinwerk. Die zahlreichen kleineren über Keller, Erd- und Obergeschoss verfügenden Bauten blieben hinter dem Vorderhaus verborgen und unterschieden sich von einem Kemladen höchstens durch die Wandstärke. Dagegen wurde das aus dem 14. Jahrhundert stammende Steinwerk des Ledenhofes im 15. Jahrhundert auf sieben-Stockwerke erhöht und überragt somit auch den zu Beginn des 16. Jahrhunderts errichteten Palasbau des Bürgermeisters Hinrìch von Leden. ${ }^{205}$ In seinen Ausmaßen und der räumlichen Wirkung erinnert dieses Steinwerk als eines der wenigen, die im Umkreis der Katharinenkirche erhalten blieben, schon eher an süddeutsche und norditalieni-

\footnotetext{
${ }^{201}$ Vgl. IGEL, Auf der Spur des Stadt-Raums (wie Anm. 43), S. $157 \mathrm{f}$.

${ }^{202}$ Die Kartierung gibt nur dic ungefahre Wohnlage wieder, da eine Parzellengenauigkeit in der Regel nicht zu erreichen ist. Genaue Zuordnungen sind allerdings zum Beispiel für die Poggenburg und den Ledenhof möglich.

${ }^{203}$ Die Osnabrücker Ritterschaft wählte auch schon zuvor ihren städtischen Wohnsitz häufiger in diesem Bereich in der Nachbarschaft der führenden Familien der Stadt, so veräußerte Johann Ertmann schon 1540 seinen Hof in der Hakenstraße an die Familie von dem Bussche, vgl. HoffmanN, Grenzen von Aufstieg und Etablierung (wie Anm. 125), S. 37; zu den Adelhöfen, vom BRUCH, Die Rittersitze des Fürstentums Osnabrück (wie Anm. 136), S. 414-459.

${ }^{204} \mathrm{Vgl}$. IGEL, Auf der Spur des Stadt-Raums (wie Anm. 43), S. $157 \mathrm{f}$.

${ }^{205}$ Vgl. Roswitha PopPE, Der Ledenhof in Osnabrück, Osnabrück 1978, S. 24-32.
} 
sche Turmhäuser. ${ }^{206}$ Für die stark unterschiedliche soziale Bewertung von Steinwerken sprechen auch die Nennungen in den Steuerverzeichnissen. Sie erscheinen nämlich vor allem dann, wenn sie vermietet wurden. Mieterinnen waren in fast allen Fällen alleinstehende Frauen bzw. Witwen, die keine oder nur geringe Steuern zahlten. ${ }^{207}$

\subsection{Soziale Struktur und städtische Sakrallandschaft}

Die Konzentration der Ratsfamilien auf das Viertel um St. Katharinen, wie sie aus der Kartierung ihrer Wohnhäuser um 1447 (Abb. 10), aber aus den Quellen auch für die Zeit davor und danach zu erkennen ist, ${ }^{208}$ korreliert zwar nicht mit der heute nachvollziehbaren Verteilung der Steinwerke, dafür aber mit der städtischen Sakrallandschaft, wie sie sich bis zur Reformation entwickelte (Abb. 2). Die Katharinenkirche entstand um 1200 als Zentralbau in einem möglicherweise noch dünn besiedelten Teil der Altstadt, zwischen 1218 und 1248 erfolgte die Erhebung zur Pfarrkirche für den südwestlichen Bereich der Altstadt und den Nordwesten der gerade entstehenden Neustadt. ${ }^{209}$ Vermutlich schon vor 1250 ließen sich nördlich der Kirche die Franziskaner nieder, die zuvor über ein Konvent im dicht bebauten Gebiet nördlich des Marktes verfügten. ${ }^{210}$ In einem aus den 1260er Jahren stammenden Testament wird erstmals ein Beginenhaus bei den Franziskanern genannt, wobei nicht klar ist, ob sich dies auf das Kloster bei St. Katharinen oder den ursprünglichen Konvent zwischen Turm- und Lohstraße bezog. ${ }^{211}$ Ein Konvent von fünf Beginen bei St. Katharinen ist dann für 1314 belegt, die weitere Zukunft dieses Hauses verbleibt aber im Dunkeln. Auch das 1306 und 1308 genannte Beginenhaus Broke lag im Katharinenkirchspiel. Die eigentliche Gründungswelle der großen Beginenhäuser in diesem Teil der Stadt begann 1332 mit dem Haus Haltering, dem 1347 das Haus Wedering und vor 1403 das Haus

\footnotetext{
${ }^{206}$ Dass dieser Vergleich mit den Geschlechter- oder Streittürmen nicht gänzlich abwegig ist, zeigt ein Blick nach Bremen: Hier berichtet die um 1400 verfasste Chronik der Domherren Gerd Reynesberch und Herbord Schene nicht nur vom Bau der großen "Steinkammern" in den Jahren um 1200, sondern auch, dass diese als Akt der Bestrafung abgebrochen wurden, vgl. Rudolf STEIN, Das Bürgerhaus in Bremen (Das deutsche Bürgerhaus Bd. 13), Tübingen 1970, S. 25.

${ }^{207} \mathrm{Vgl}$. IGEL, Auf der Spur des Stadt-Raums (wie Anm. 43), S. 156.

${ }^{208}$ Vgl. IGEL, Möglichkeiten (wie Anm. 131).

${ }^{209}$ Vgl. IGEL, Gewachsen oder geplant (wie Anm. 9); DERS, Von der vorkommunalen zur kommunalen Stadt (wie Anm. 31).

${ }^{210} \mathrm{Vgl}$. Roland PIEPER, Die Kirchen der Bettelorden in Westfalen (Franziskanische Forschungen 39), Werl (Westf.) 1993, S. 117-124.

${ }^{211}$ Osnabrücker Urkundenbuch Bd. 4, Nr. 692 - zwischen 1264 und 1268; vgl, IGEL. Zentren (wie_Anm 28), S, 23-25.
} 
Bloming folgten. Schließlich erwarben 1445 mehrere Schwestern von der Familie Dumpstorp ein Haus südlich der Katharinenkirche, das 1449 als Haus Dumpstorping vom Rat die Bestätigung erhielt. ${ }^{212}$ Dieses Haus schloss sich bereits 1462 als Kloster Marienstätte dem Augustinerorden an und erhielt eine eigene Kapelle, die 1474 geweiht wurde. Die Beginen des Hauses Bloming schlossen sich dann um 1500 als Kloster Blumenthal dem Franziskanerorden an und errichteten anschließend gegen den ausdrücklichen Willen von Franziskanern, Rat und Domkapitel eine eigene Kapelle. ${ }^{213}$ Die zu Beginn des 15. Jahrhunderts erfolgte Gründung eines Fraterhauses, die dann aber am Widerstand des Rates scheiterte, lag im Nordwesten der Neustadt vor der Katharinenpforte. ${ }^{214}$ Ebenfalls hier befand sich der 1378 erworbene Hof des Iburger Benediktinerklosters. ${ }^{215}$ So drängten sich um den Kirchhof von St. Katharinen am Vorabend der Reformation die Kirchen und Kapellen von drei Klöstern sowie zwei Beginenhäuser. St. Katharinen selbst erhielt in den Jahrzehnten um 1500 mit dem Bau des massiven Kirchturms, der noch heute das Stadtbild dominiert, ihre endgültige Gestalt. Als Kirchenräte standen hinter diesem Neubau unter anderem die Altstädter Bürgermeister Ertwin Ertmann und Hinrich von Leden sowie der Neustädter Bürgermeister Hinrich Vrese. Diese prägten als führende Persönlichkeiten im Osnabrücker Rat des ausgehenden 15. Jahrhunderts auch den Neubau des Altstädter Rathauses und der Umgestaltung des Marktplatzes. Gemeinsam mit ihren Amtskollegen Gottschalk von Ankum und Gerd von Dumpstorp ließen sie ihre Wappen in Kapitelle des neuen Rathauses und somit in das historische Gedächtnis der Stadt schneiden, wofür sie 148912 1/2 Mark zahlten. ${ }^{216}$ Nach der Fertigstellung der gotischen Spitzhaube überragte der Katharinenkirchturm mit einer Höhe von 104 m seit 1511 alle übrigen Kirchen mit großem Abstand. Von welcher Bedeutung diese bauliche Wirkung war, verdeutlicht die Reaktion des Osnabrücker Domkapitels, das noch im selben Jahr einen Baumeister als Gutachter aus Bielefeld kommen und in den folgenden Jahren den massiven Südwestturm des Domes errichten ließ, dessen Spitze bedingt durch die Reformation die Höhe des Katharinenkirchturms nur knapp verfehlte. ${ }^{217}$ Augenfällig und in diesem Zusammenhang von wesentlicher Bedeutung ist dabei, dass die Katharinenkirche und nicht die

\footnotetext{
${ }^{212}$ Vgl. IGEL. Zentren (wie Anm. 28), S. 25.

${ }^{213}$ Vgl. Wilhelm BERNING; Das Brstum Osnabrück vor Einführung der Reformation (1543)

(Das Bistum Osnabrück Bd. 3), Osnabrück 1940. S. 192-196.

${ }^{214} \mathrm{Vgl}$. ROTHERT, Geschichte (wie Anm. 34), S. $241 \mathrm{f}$.

${ }^{215}$ Osnabrücker Urkundenbuch Bd. 5, Nr. 185 - 1378 März 27.

${ }^{216} \mathrm{Vgl}$. EBERHARDT. Städtischer Alltag (wie Anm. 36), S. 87.

${ }^{217} \mathrm{Vgl}$. Ralf-Maria GuNTERMANN, Turmbas und Totengedenken. Die Domfabrik zu Osnabrück im späten Mittelalter (Das Bistum Osnabrück Bd. 5), Osnabrück 2003, S. 93-102.
} 
am Markt gelegene Marienkirche, in der der Rat ein Gestühl besaß und vor der jährlichen Wahl die Messe_besuchte, ${ }^{218}$ zum baulichen Gegenspieler des Domes wurde. Die großen Baumaßnahmen des ausgehenden 15. Jahrhunderts betrafen zwar Markt und Rathaus, nicht aber die dort gelegene Pfarrkirche, sondern jene, in deren Pfarrei die Mehrzahl der führenden Familien debte. Hintergrund hierfür war auch die Osnabrücker Ratsverfassung, die sich an den Leischaften als Stadtviertel orientierte und der Marktleischaft nur zwei der zwölf Altstädter Ratssitze zugestand, während im Umfeld der Katharinenkirche, bei der Johannisleischaft und Butenburg aneinander grenzten, insgesamt acht Ratsherren wohnen konnten. In diesem Bereich standen zudem großräumigere Grundstücke zur Verfügung. ${ }^{219}$ Schon bei der Einwölbung der neu errichteten Hallenkirche im ersten Viertel des 15. Jahrhunderts kann eine starke Beteiligung von Ratsfamilien beobachtet werden. Um die Schlusssteine herum finden sich neben den Wappenschildern der zu dieser Zeit amtierenden Bischöfe Heinrich I. von Holstein (1402-1410) und Otto II. von Hoya (1410-1424) unter anderem jene der verschiedenen Zweige der Familie von Dumpstorp sowie der Familien von Brinke, Buck, von Gramberg und von Leden, die allesamt im 14. und 15. Jahrhundert an führender Stelle im Osnabrücker Rat standen. ${ }^{220}$

\section{Stadt-Raum und Stadtgesellschaft - ein Fazit}

Die Rekonstruktion des städtischen Raumgefüges, des Verlaufs und der Funktion der Straßen, Plätze und Bauten, ihrer Gestalt und Nutzung, bildet die entscheidende Grundlage, um die soziale Struktur einer Stadt in ihrer räumlichen Dimension fassen zu können. Möglich ist dieser Schritt auf der Basis verschiedener Quellen für die meisten Städte, wie an den Beispielen Greifswald und Osnabrück gezeigt werden sollte - auch dort wo keine oder nur wenige Steuerverzeichnisse überliefert sind. Dass auch hier je

\footnotetext{
$218 \mathrm{Vgl}$. POECK. Rituale der Ratswahl in westfälischen Städten (wie Anm. 134), S. 212-214.

${ }^{219} \mathrm{Vgl}$. IGel, Von der Straße zum Platz (wie Anm. 35), S. 192; zu Stadtvierteln vgl, auch Jörg RoGGE, Viertel, Bauer-, Nachbarschaften, Bemerkungen zur Gliederung und Funktion des Stadtraums im 15. Jahrhundert, in: Hanse - Städte - Bünde. Die sächsischen Städte zwischen Elbe und Weser um 1500, hg. von Matthias PuHLE, Magdeburg 1996, S. 231-240; Robert JüTTE, Das Stadtviertel als Problem und Gegenstand der frühneuzeitlichen Stadtgeschichtsforschung, in: BDLG 127, 1991, S. 235-269.

${ }^{220} \mathrm{Vgl}$. Siegfried SALZMANN, Die Baugeschichte der Pfarrkirche St. Katharinen zu Osnabrück, Diss. phil. Göttingen 1957, S. 80-86. Zum engen räumlichen Verhältnis zwischen führenden Familien und Kirchen vgl. am Beispiel Hamburgs Frauke PLATE, Biddet vor dat geslecht. Memoria und Repräsentation im mittelalterlichen Hamburg, in: Gemeinschaft und Geschichtsbilder im Hanseraum, hg. von Thomas HILL und Dietrich W. POECK (Kieler Werkstücke E/1), Frankfurt (Main) 2000, S. 6I-I00, hier S. $74 \mathrm{f}$.
} 
nach Quellenlage eine unterschiedliche Detailtiefe zu erreichen ist, liegt auf der Hand. Als Ergebnis bietet sich aber auf jeden Fall eine Vergleichbarkeit verschiedener Städte auf einer Minimalebene.

Dieses Raumgerüst lässt sich mit den verfügbaren prosopographischen Quellen um die wesentliche soziale Komponente erweitern. Auch hier ist eine möglichst große Breite der zu berücksichtigenden Quellen wünschenswert, was aber je nach Größe der Stadt an die Grenzen einer sinnvollen und überschaubaren Machbarkeit stoßen dürfte. Wichtig erscheint die starke Berücksichtigung von Quellen jenseits der statistisch scheinbar leicht auszuwertenden Steuerverzeichnisse, die Betrachtung von Sozialgruppen im Blick auf ihre innere Struktur sowie ihre Stellung und Funktion innerhalb der Stadt(-gesellschaft), anstatt ein statistisches Ordnungsschema im Sinne einer überschaubaren Schichtung auf eine vormoderne Gesellschaft zu oktroyieren.

Es sollte also nicht die Einzelperson bis ins Detail auf ihre soziale Stellung untersucht, sondern wieder die Stadt in ihrer Gesamtheit von Menschen und Bauwerken in Augenschein und zur Grundlage einer sozialräumlichen Untersuchung genommen werden. 